\title{
Bilder zum Hören - Bilder zum Sehen: Lukians Ekphraseis und die Rekonstruktion antiker Kunstwerke
}

\author{
BARBARA E. Borg
}

Unsere Kenntnis der Vergangenheit ist fragmentarisch. Diese Feststellung ist an Banalität wohl kaum zu überbieten, und doch stellt sie nicht nur das notorische Lamento aller Altertumsforscher sondern zugleich ihre größte Herausforderung und eine Quelle der Faszination ihres Gegenstandes dar. Im Falle der Klassischen Archäologie wird durch die antiken literarischen Nachrichten über großartige, jedoch für immer verlorene Kunstwerke diese Fragmenthaftigkeit um so schmerzlicher, während zugleich ihre rekonstruierende Überwindung in greifbare Nähe zu rücken scheint.

So lesen wir etwa wieder dankbar Pausanias, nachdem wir erkannt haben, dass die auffällige Lückenhaftigkeit seiner Beschreibung Griechenlands offenbar nicht auf Unkenntnis, mangelnde Autopsie oder schlicht Schlamperei eines verhinderten Baedekerautors zurückzuführen ist, sondern dass Pausanias Vollständigkeit offenbar gar nicht anstrebte. Vielmehr scheint es, wie zuerst Jas Elsner gezeigt hat, dass er eine Art Topographie griechischer Identität verfassen wollte, in der panta ta bellenika nur das bezeichnet, was die - überwiegend vergangene! - griechische Größe ausmachte. ${ }^{1}$ Zum Leidwesen der Archäologen gehörten jedoch die ästhetischen Qualitäten von Bildwerken für Pausanias nicht unbedingt dazu und so klingen seine Beschreibungen der Kunstwerke selbst denn auch eher lapidar. ${ }^{2}$

Als zuverlässiger Zeuge antiker Denkmäler gilt auch Plinius, der vor allem im 34. und 35. Buch seiner Naturalis Historia eine Fülle von heute zumeist verlorenen Kunstwerken samt den Namen ihrer Schöpfer erwähnt. Seine Angaben zu Malweisen und Erfindungen einzelner Künstler sind zweifellos von großem Wert und verraten über das technische Interesse hinaus durchaus einen gewissen Sinn

1 J. Elsner, Pausanias: A Greek Pilgrim in the Roman World, Past and Present 135, 1992, 3-29; ders., From the pyramids to Pausanias and Biglet: monuments, travel and writing, in: S. Goldhill - R. Osborne (Hgg.), Art and text in ancient Greek culture (Cambridge 1994), 224-254; ders., Art and the Roman Viewer (Cambridge u. a. 1995) 125-155; für verwandte Interpretationsansätze s. auch S. Alcock (Hg.), Pausanias: Travel and Memory in Roman Greece (Oxford u. a. 2001).

2 Dies wurde in älteren Arbeiten auch mit Missbilligung hervorgehoben, s. z. B. T. Birth, Laienurteil über die bildende Kunst bei den Alten, Marburger Akademische Reden 7 (Marburg 1902); H. Blümner, Archäologische Studien zu Lukian (Breslau 1867) 2. 
für Ästhetik. Doch so überschwänglich sein Lob einzelner Künstler und Werke gelegentlich ist, so fallen die Beschreibungen bei ihm oft sogar noch knapper aus als bei Pausanias, wenn er sich nicht ganz auf reine Aufzählungen beschränkt. So liegt es offensichtlich auch nicht in seiner Absicht, dem Leser die Kunstwerke durch eine entsprechend anschauliche Schilderung vor sein geistiges Auge zu stellen.

Genau dies tut nun allerdings ein Autor in so meisterhafter Weise, dass man seine schillernde Persönlichkeit und sein irritierendes Spiel mit Worten und Wahrheiten nur zu gern zu vergessen bereit ist. „Mit Recht werden Lukians Nachrichten und Urteile über Werke der bildenden Kunst sehr hoch geschätzt - verdanken wir doch diesem Schriftsteller einige Ecksteine zum Aufbau der griechischen Kunstgeschichte ", so etwa Friedrich Koepp, ,... es bleibt eine Tatsache, dass diese Zeugnisse zum Wertvollsten gehören, was uns von antiker Kunstbetrachtung erhalten ist. ${ }^{{ }_{3}}$ Dass diese Ansicht über den Satiriker des 2.Jhs.n. Chr. im Prinzip auch heute noch geteilt, wenn auch weniger emphatisch vorgetragen wird, lehrt der Blick in die archäologische Literatur wie in neuere philologische Kommentare. ${ }^{4}$

Lukians vielleicht berühmtestes Gemälde ist die Diabole, die Verleumdung, des Malers Apelles, die in Archäologie und Kunstgeschichte bis heute als Prototyp und ältestes Beispiel einer echten Allegorie gilt, und damit wahrhaftig ein Eckstein nicht nur der griechischen, sondern der europäischen Kunstgeschichte insgesamt wäre (vgl. Abb. 1).

Rechter Hand sitzt ein Mann, der so ansehnliche Ohren hat, dass ihnen wenig zu Midasohren fehlt, und schon von ferne der auf ihn zukommenden Verleumdung ( $\delta \iota \alpha-$ $\beta o \lambda \eta \dot{\eta})$ die Hand entgegenreicht. Zu beiden Seiten stehen zwei Frauenspersonen neben

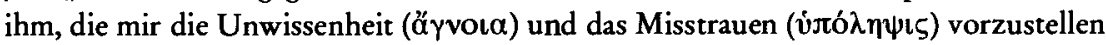
scheinen. Diesem nähert sich von der anderen Seite die Verleumdung in Gestalt eines

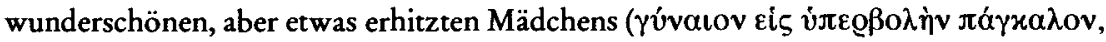

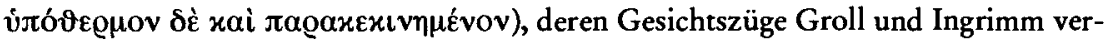
raten; sie trägt in der linken Hand eine brennende Fackel und schleppt mit der Rechten einen jungen Menschen bei den Haaren herbei, der die Hände gen Himmel streckt und

3 F. Koepp, Ogmios. Bemerkungen zur gallischen Kunst, Bonner Jabrbücher 125, 1919, 38-73, hier 38; Bei anderen wird Lukian geradezu zum Kunstkenner schlechthin, z. B. Blümner (s. Anm. 2) passim; V. Andò, Luciano critico d'arte (Palermo 1975).

4 S. z. B. H. A. Shapiro, The Origins of Allegory in Greek Art, Boreas 9, 1986, 4-23, der die Diabole als „earliest and best known example ${ }^{\alpha}$ einer echten Allegorie bezeichnet (S. 4); I. Scheibler, Griechische Malerei der Antike (München 1994) mit ihren Rekonstruktionsversuchen S. 43-45; J. Bompaire, Lucien écrivain. Imitation et création (Paris 1958) 713-718; ders., Lucien. CEuvres. Tome I (Paris 1993) 56 (zum HeraklesOgmios); Tome II (Paris 1998) 137 (zur Diabole); St. Altekamp, Zu den Statuenbeschreibungen des Kallistratos, Boreas 11, 1988, $110 \mathrm{f}$. 


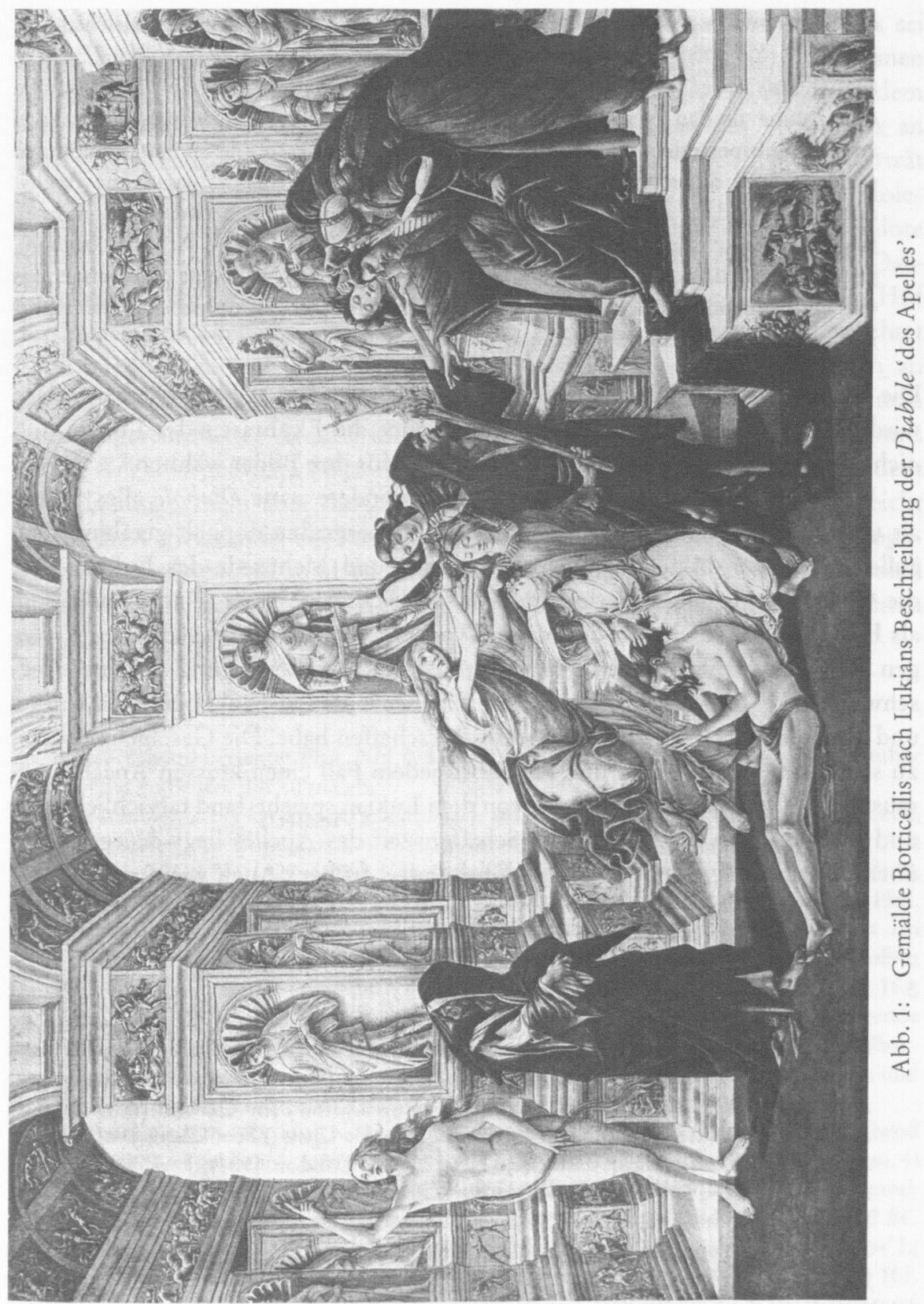


die Götter zu Zeugen seiner Unschuld anruft. Vor ihr geht ein hässlicher, bleichsüchti-

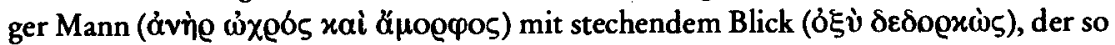
aussieht, als ob er von einer langwierigen Krankheit ausgezehrt wäre und den man ohne Mühe als den Neid ( $\varphi \vartheta$ óvo $)$ erkennt. Hinter der Verleumdung gehen zwei andere Weibspersonen, die sie aufzuhetzen, zu unterstützen und sie herauszuputzen scheinen, und deren eine (wie mir der Ausleger des Gemäldes sagte) die Arglist

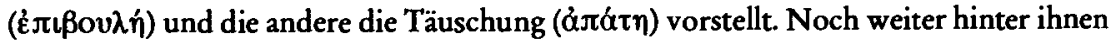

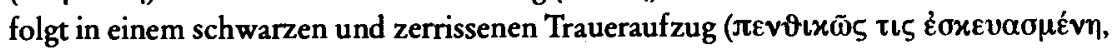

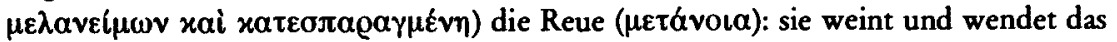
Gesicht beschämt vor der Wahrheit, die sich ihr nähert, ab, als ob sie sich scheute, ihr in die Augen zu sehen. (Übersetzung Wieland)

Die Beschreibung ist detailreich und anschaulich, so dass sich niemand wundern wird, dass Maler und Zeichner der Renaissance die Ekphraseis des Lukian und nicht die des Plinius oder Pausanias als Vorlage für ihre Bilder wählten. ${ }^{5}$

Und doch sind Lukians Bilder und insbesondere seine Diabole alles andere als unproblematisch. Letztere ist im Text gewissermaßen doppelt gerahmt. Den äußeren Rahmen bildet die eigentliche Lehr- und Mahnrede des Lukian über die Gefahren von Neid, Verleumdung und Leichtgläubigkeit. Darin findet sich als Exempel die Geschichte des Malers Apelles, der von einem neidischen Kollegen bei dem leichtgläubigen Pharao Ptolemaios der Beteiligung an einer Verschwörung beschuldigt worden sei, zuletzt aber seine Unschuld beweisen konnte und daraufhin das oben zitierte Gemälde geschaffen habe. Die Geschichte ist fast zu schön um wahr zu sein und enthält in jedem Fall einen krassen Anachronismus. Der Aufstand des Theodotos, von dem Lukian spricht, fand tatsächlich statt, und zwar im Jahr 219 v. Chr. Die Schaffenszeit des Apelles liegt dagegen nach übereinstimmenden Zeugnissen ein Jahrhundert früher. ${ }^{6}$ Auch war Apelles Hof-

5 Albertis Empfehlung in seinem Traktat über Malerei, erstmals lateinisch publiziert 1435 und ein Jahr später in italienischer Übersetzung, markiert den Begin einer reichen kreativen Rezeption. Zur neuzeitlichen Rezeption der Bilder Lukians s. D. Cast, Lucianic and Pseudo-Lucianic themes in the Renaissance: A Study in Renaissance Humanism (New York 1970); D. Rosand, Ekphrasis and the Generation of Images, Arion 1, 1990, 61-105; speziell zur Diabole s. D. Cast, The Calumny of Apelles. A Study in the Humanist Tradition (New Haven/London 1981); J.M. Massing, Du texte à l'image. „La Calomnie" d'Apelle et son iconographie (Strasbourg 1990); zum Herakles-Ogmios F. R. Varwig, Raffaels Herakles 'Ogmios' - Ein Paradeigma zur Ikonologie des sprachlichen Wohlklangs, in: F. R. Varwig (Hg.), AINIr MA. Festschrift für Helmut Rabn (Heidelberg 1987) 35-75.

6 Der Neue Pauly 12/1 (2002) s. v. Theodotos Nr. 3 (W. Ameling). Der Anachronismus erstmals bemerkt von J. Toll in: Lucianus Samosatensis de Calumnia cum notis Jacobi Tollii (Leiden 1677) 10 Anm. 1, und diskutiert von P. Bayle, Dictionnaire historique et critique I (Rotterdam 1697) 300-301; vgl. Massing (s. Anm. 5) 16. 
maler Alexanders des Großen. Plinius ( $\mathrm{NH} \mathrm{35,89)} \mathrm{berichtet} \mathrm{zwar,} \mathrm{Apelles} \mathrm{sei}$ durch einen Sturm nach Alexandria verschlagen worden, wo ihm durch einen Nebenbuhler ein Streich gespielt wurde. Doch bestand dieser bei Plinius in dem vergleichsweise harmlosen Scherz, den Maler ohne Wissen des Ptolemaios an dessen Tafel zu laden. Apelles klärt das Missverständnis auf, indem er das Porträt des Spaßvogels mit einem Stück Kohle auf die Wand skizziert, woraufhin Ptolemaios den Urheber des Affronts sofort identifiziert. Hier dient die Anekdote letztlich dazu, die Ähnlichkeit der von Apelles gemalten Porträts mit den Dargestellten hervorzuheben.7 Von einem längeren Aufenthalt des Apelles am Hof des Ptolemaios oder irgendwelchen Bildern, die er dort gemalt hätte berichtet Plinius jedoch ebenso wenig wie irgendein anderer Autor, obgleich doch an Apelles und zumal an seinem Leben lebhaftes Interesse bestand. ${ }^{8}$ Zumeist hat man diese Ungereimtheiten damit erklärt, Lukian habe bewusst oder aus Unkenntnis falsche Angaben gemacht. Nach Auffassung einiger ist die Anekdote mitsamt dem Bild glaubhaft, nicht aber die Zuschreibung an Apelles. Die Mehrheit streicht jedoch die Verleumdung bei Ptolemaios, wodurch das Bild nicht nur der europäischen Kunstgeschichte, sondern auch dem Apelles erhalten bliebe, dem eine solch außergewöhnliche Bilderfindung eher zugetraut wird als einem unbekannten Maler. $^{9}$

7 Entsprechend berichtet Plin. $N H$ 7, 125; 35, 85, Alexander habe jedem anderen außer Apelles verboten, ihn zu malen.

8 Die testimonia bei Overbeck belaufen sich auf die stattliche Zahl von 80 (J. Overbeck, Die antiken Schriftquellen zur Geschichte der bildenden Künste bei den Griechen [Leipzig 1868] Nr. 1827-1906). Von diesen berichtet einzig noch Tzetzes Chiliades 8, 394 = Overbeck Nr. 1838 von einem Aufenthalt des Apelles am ptolemäischen Hof, doch beruft er sich hierfür ausdrücklich auf Lukian. Ein längerer Aufenthalt am Ptolemäerhof wird dennoch oft mit großer Zuversicht voraus gesetzt, s. z. B. J.J. Pollitt, The Art of Ancient Greece: Sources and Documents (Cambridge, MA, u. a. 1965) 163; Der Neue Pauly 1 (1996) 829f. s.v. Apelles Nr. 4 (N. Hoesch); s. auch die folgende Anm. Eine Bearbeitung der Künstleranekdoten und -biographien in der antiken Überlieferung, welche auch den literarischen Charakter, die Interessenlage der Autoren und die Topik dieser 'Textgenres' einbeziehen würde, ist ein dringendes Desiderat.

9 Die wenigen Zweifler, welche auch die Existenz des Bildes bestritten, sind weitgehend ohne Einfluss geblieben, s. Massing (s. Anm. 5) 17 mit Anm. 11-12. Scheibler (s. Anm. 4) 44 streicht nur den historischen Zusammenhang mit dem Theodotos-Aufstand; J. Onians, Art and Thought in the Hellenistic Age. The Greek World View 350-50 BC. (London 1979) $97 \mathrm{f}$. verlegt mit dem Bild auch die Anekdote an den Hof Ptolemaios' I.; s. die Übersicht über weitere ältere Erklärungsversuche bei Scheibler (s. Anm. 5) $16 \mathrm{f}$. Massing (s. Anm. 5) 20-22 schlussfolgert, dass die Zuschreibungsfrage allein aufgrund der Schriftquellen kaum abschließend zu beantworten sei, ist jedoch von der Existenz des Bildes vor allem aufgrund zahlreicher literarischer Belege für die betreffenden (und verwandte) Personifikationen überzeugt; ähnlich Shapiro (s. Anm. 4) 5 Anm. 6. Zu die- 
Nun ist diese Lösung keineswegs undenkbar, aber ist sie damit schon plausibel oder gar wahrscheinlich? Zum Vergleich hat man für die Gestalt der Diabole auf die Ikonographie der Erinnyen in der unteritalischen Vasenmalerei verwiesen, für die Komposition auf die Audienzszene auf der sog. Perservase (Abb. 2) und, als Beispiel einer aufgelockerteren Darstellungsweise und des Themas auf den Fries in Raum C der Villa Farnesina, der Gerichtsszenen zeigt und vielfach auf eine hellenistische Vorlage zurückgeführt wird. ${ }^{10}$ Unabhängig davon, ob man an die Existenz einer solchen bildlichen Vorlage glaubt oder nicht, besteht das Ungewöhnliche der Bilderfindung der Diabole jedoch nicht in der Art der Komposition oder der Wahl des Themas, sondern in der Art der Figuren, ihrer bildlicher Charakterisierung und ihrer Einbindung in einen narrativen Zusammenhang. Die Besonderheit des Bildes hat man immer bemerkt, doch nie genauer analysiert, und so wurde übersehen, dass dieses Bild nicht nur ungewöhnlich, sondern völlig singulär wäre - sowohl im 4.Jh. v. Chr. als auch in der gesamten griechisch-römischen Kunst.

Zunächst fällt bei der Wahl der Personifikationen auf, dass die Mehrzahl im Bestand der antiken Bildüberlieferung überhaupt nicht nachzuweisen ist: nämlich Aletheia, Diabole, Epiboule, Hypolepsis und Metanoia. ${ }^{11}$ Agnoia, Apate und Phthonos sind zwar vereinzelt belegt, ihre Ikonographie entspricht jedoch in keinem Fall genau jener der lukianischen Beschreibung. Während für Agnoia offenbar überhaupt keine eigene Ikonographie entwickelt wurde, erscheint Apate einmal in einer erinnyenähnlichen Aufmachung (Abb. 2) und einmal ohne spezifi-

sem Argument s.u. Anm. 48, zu den von ihr angeführten Bildern s. im Folgenden. Anders erging es bezeichnenderweise Seneca, der in seinen Controversiae $(10,5)$ behauptet, der Maler Parrhasios sei angeklagt gewesen, einen von Philip V. erworbenen alten Olynther gefoltert zu haben, um eine möglichst realistische Vorlage für ein Bild des Prometheus zu erhalten. Der Fall ist insofern ähnlich gelagert, als auch diese Anekdote nur einmal überliefert ist und einen Anachronismus enthält (Parrhasios war bei der Eroberung Olynths 348 wohl bereits ca. 30 Jahre tot). In diesem Fall reichten die Gründe jedoch aus, Geschichte und Bild allgemein für fiktiv zu halten - vermutlich wegen ihres abstoßenden Charakters.

10 Massing (s. Anm. 5) 22f.; Scheibler (s. Anm. 4) 44. Zur Perservase s. H. Gabelmann, Antike Audienz- und Tribunalszenen (Darmstadt 1984) 76-80; zu den Farnesina-Fresken s. I. Bragantini - M. de Vos, Museo Nazionale Romano. Le Pitture II 1. Le decorazioni della Villa romana della Farnesina (Rom 1982) Taf. 134-161; Gabelmann (wie oben) 151 f.; Scheibler (s. Anm. 4) 44.

11 Vgl. Lexicon Iconographicum Mythologiae Classicae (= LIMC) I (1981) 486f. s.v. Aletheia (S. Settis); LIMC III (1986) 386 s. v. Diabole (J.-R. Gisler); LIMC III (1986) 803 s.v. Epiboule (J.-R. Gisler); LIMC V (1990) 609 s.v. Hypolepsis (J.-R. Gisler); LIMC VI (1992) 561f. s.v. Metanoia (E. Polito). Mit Metanoia wurden vorschlagsweise zwei Reliefdarstellungen identifiziert (LIMC ebd. Nr. 2 und 3), in keinem Fall ist jedoch eine Beischrift erhalten, welche die Benennung sichern könnte. 


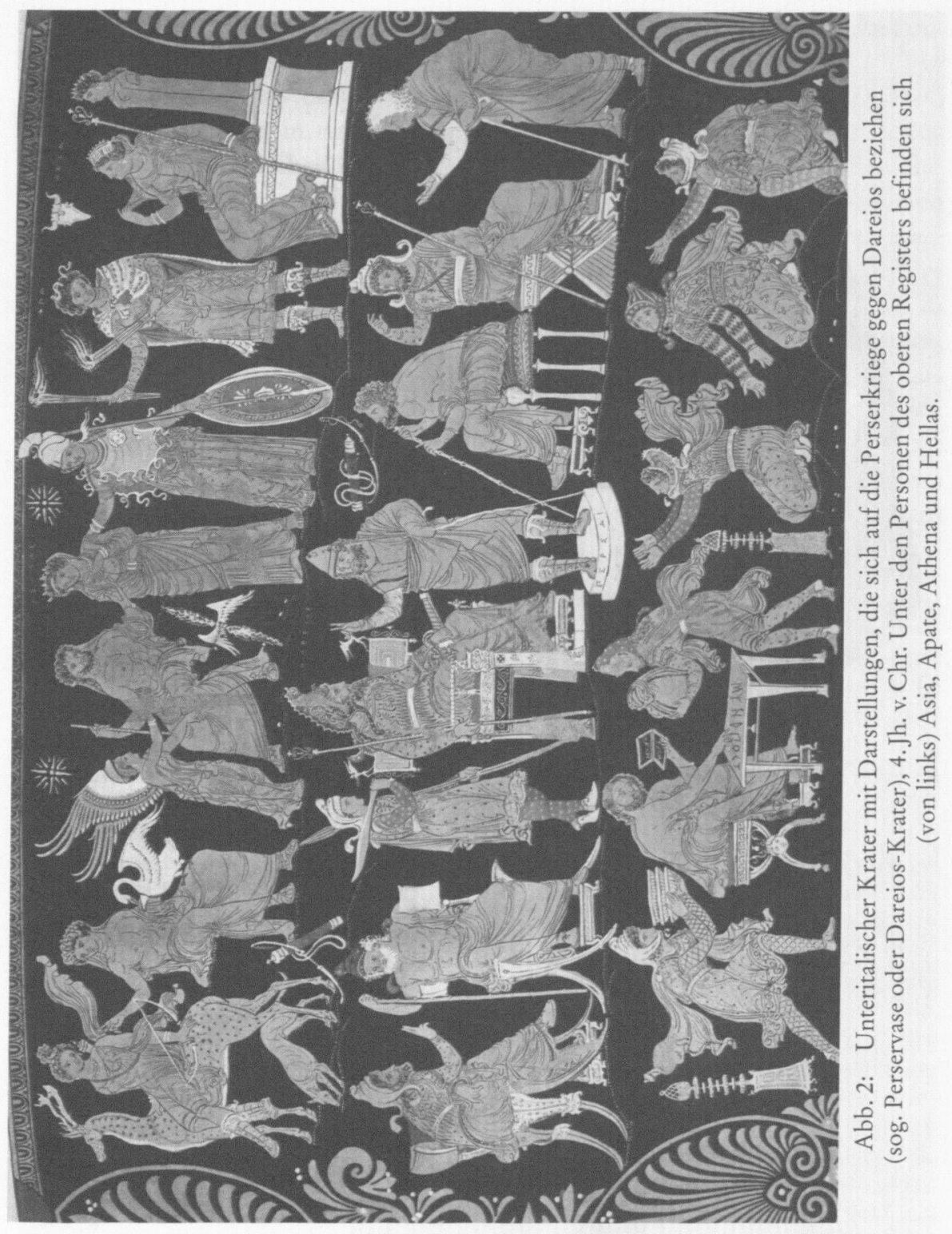




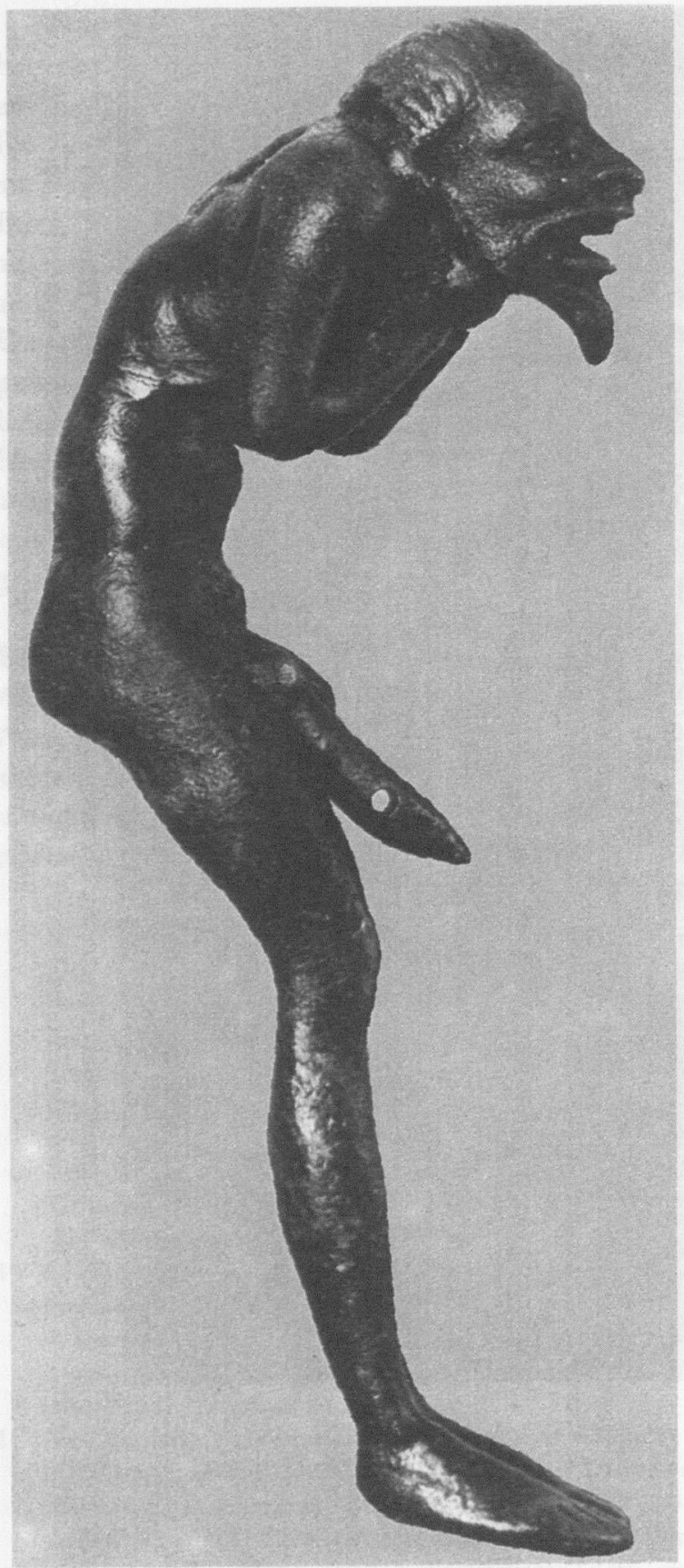

Abb. 3: Bronzestatuette des Phthonos (Neid), kaiserzeitlich. 
sche Merkmale; ${ }^{12}$ Phthonos wird als nackter Mann dargestellt, der sich selbst mit beiden Händen stranguliert (Abb. 3-4). ${ }^{13}$

Wichtiger noch als diese Beobachtungen ist die einzigartige Konstellation der Personifikationen in einem vielfigurigen narrativen Zusammenhang. Selten werden in der griechischen Kunst überhaupt mehr als ein oder zwei Personifikationen gemeinsam dargestellt und fast nie sind sie unter sich. In der Regel besitzen sie eine kommentierende Funktion innerhalb mythischer oder historischer Darstellungen. So etwa auf einem von Plinius ( $N H 35,138)$ erwähnten Gemälde des Aristophon, das offenbar jene Episode aus dem Trojanischen Krieg wiedergab, in der sich Odysseus als Bettler verkleidet nach Troja einschlich. Neben Priamos, Helena, Odysseus und Deiphobos waren auch Credulitas (die Leichtgläubigkeit) und Dolus (die List) dargestellt, welche sich auf die das Geschehen leitenden Motivationen und Charakterzüge bezogen. Dieselbe Funktion haben Apate auf der sog. Perservase (Abb. 2), wo sie sich wohl auf die Verblendung bezieht, welche die Perser zu ihrem Kriegszug verführt hat, ${ }^{14}$ dieselbe Personifikation auf einem

12 Zu Agnoia: LIMC I (1981) 302f. s.v. Agnoia (F. Canciani); die ebenda aufgezählten Darstellungen mit zweifelhafter Benennung wurden von K. Lehmann, Ignorance and Search in the Villa of the Mysteries, Joumal of Roman Studies 52, 1962, 62-68, in die Diskussion eingeführt, stammen aber anders als die inschriftlich gesicherten Darstellungen alle aus dem dionysischen Bereich. Sie stimmen weder untereinander noch mit den sicheren Darstellungen ikonographisch genau überein. Die Gestalten scheinen eher ein allgemeines Darstellungsschema je nach Kontext zu variieren. Die dionysischen Bilder sollten daher aus der Diskussion ausgeschlossen werden.

Zu Apate: LIMC I (1981) 875f. s.v. Apate (G. G. Belloni) mit zwei inschriftlich gesicherten Darstellungen auf apulischen Vasen (der aber das lukianische Gemälde nicht einmal unter den Schriftquellen erwähnt).

13 LIMC VIII (1997) 992-996 s.v. Phthonos (J.-R. Gisler) und grundlegend K.M.C. Dunbabin - M. W. Dickie, Invidia rumpantur pectora. The Iconography of Phthonos/Invidia in Graeco-Roman Art, Jabrbuch für Antike und Christentum 26, 1983, 7-37. Die einzige sicher vorkaiserzeitliche Darstellung auf einem apulischen Volutenkrater (LIMC [wie oben] Nr. 26) zeigt Phthonos im Erostypus als Begleiter der Aphrodite beim Tod des Meleager und entspricht der Darstellung in der Diabole ebenso wenig. Die übrigen Darstellungen sind mehrheitlich erst kaiserzeitlich, lediglich eine Gruppe von Terrakotten aus der Werkstatt von Smyrna kann nur grob in das 2. Jh. v. Chr. - 2. Jh. n. Chr. datiert werden. Sie könnte daher bereits hellenistisch sein, ebenso gut jedoch wie die anderen erst kaiserzeitlich. Einen einigermaßen sicheren terminus ante quem gibt eine Bronze in Berlin, wenn die Angabe des Fundortes, Pompeji, denn zutrifft (Dunbabin - Dickie [wie oben] 22f.). Alle diese Darstellungen zeigen einen nackten, ausgemergelten Mann, der sich selbst mit beiden Händen stranguliert. Die Benennung ist durch ein Mosaik aus dem Anfang des 3. Jhs. n. Chr. gesichert (LIMC [wie oben] Nr. 16; ausführlich Dunbabin - Dickie [wie oben]).

14 LIMC I (1981) 875f. s.v. Apate Nr. 1 (G.G. Belloni); M. Schmidt, Asia und Apate, in: L. Beschi (Hg.), AIIAPXAI. Nuove ricerche e studi sulla Magna Grecia e la Sicilia 


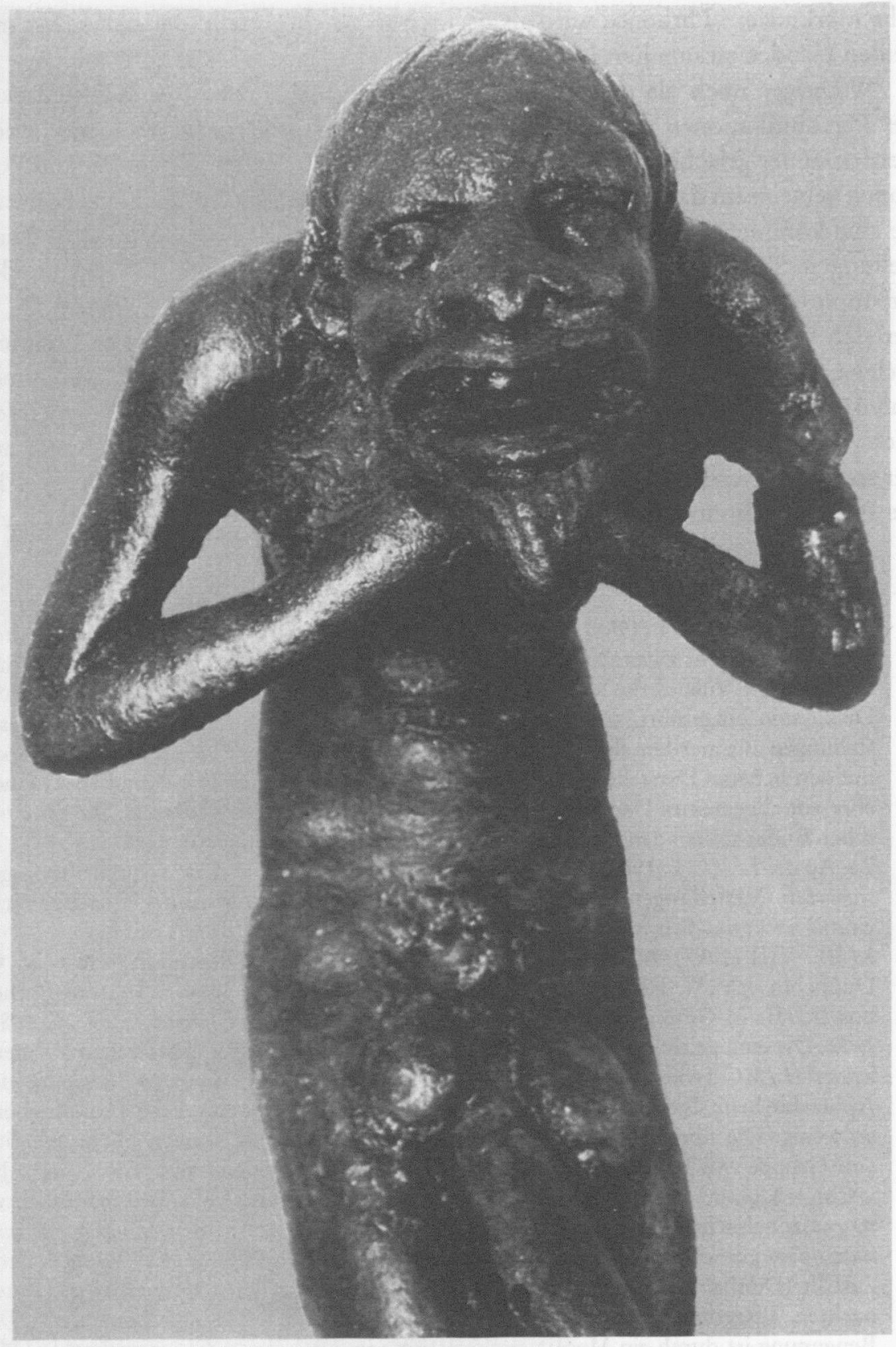

Abb. 4: Bronzestatuette des Phthonos (Neid), kaiserzeitlich. 
ebenfalls apulischen Gefäß mit dem Mythos um Tereus, Prokne und Philomela, ${ }^{15}$ der lässig gegen Aphrodite gelehnte Phthonos auf dem genannten apulischen Krater mit dem Tod Meleagers ${ }^{16}$ oder Agnoia in einem Gemälde aus einem Grab in Hermoupolis, das schon der hohen oder sogar späten Kaiserzeit angehört, wo sie die Ermordung des Laios durch den eigenen Sohn Oidipous kommentiert. ${ }^{17}$ Wenn sich Athenaios (12.534D) und Plutarch (Alcibiades 16) zufolge der athenische Politiker Alkibiades auf einem Gemälde darstellen ließ, wie er von Olympia und Pythia bekränzen wird, den Personifikationen der Orte seiner größten sportlichen Siege, so sind die Personifikationen zwar formal in der Überzahl, ihre Funktion ist jedoch wiederum die eines Kommentars zu Alkibiades und seinen Leistungen. Die Gruppe der Eirene mit dem Plutosknaben, die spätestens nach dem Frieden von $371 \mathrm{v}$. Chr. in einem neu gegründeten Heiligtum auf der Athener Agora aufgestellt wurde und den Zusammenhang von Frieden und Wohlstand symbolisiert, ist eine seltene Ausnahme, indem sie ausschließlich Personifikationen zeigt. ${ }^{18}$ Doch setzt sie trotz ihres symbolträchtigen Charakters nur eine Ausdrucksform um, die spätestens seit den Genealogien Hesiods geläufig war und durchaus nicht notwendigerweise allegorisch aufgefasst werden musste. Äußerlich ist sie ebenso wenig wie der Knabe als Personifikation erkennbar und sogar das Füllhorn lässt sich als konkretes, wenn auch bedeutungsvolles Attribut verstehen. ${ }^{19}$

Nach Anzahl der Personifikationen und dem allegorischen Charakter des Inhalts stehen der Diabole unter den erhaltenen oder sicher überlieferten Darstellungen einige Vasenbilder des späten 5.Jhs. v. Chr. am nächsten, die in unterschiedlicher Zusammenstellung meist weibliche Personifikationen und Eroten gemeinsam mit Aphrodite zeigen. ${ }^{20}$ So finden sich auf einer Londoner Pyxis (Abb. 5) von links beginnend die sitzende Eunomia, die gute Ordnung, welcher

antica in onore di Paolo Enrico Arias II (Pisa 1982) 505-520; Ch. Aellen, $A$ la recherche de l'ordre cosmique. Forme et fonction des personnifications dans la céramique italiote (Kilchberg/Zürich 1994) 109-117 Taf. 5-7.

15 LIMC I ebd. Nr. 2; Schmidt (s. Anm. 14) 518-520; Aellen (s. Anm. 14) 54f. 85 Taf. 8-9.

16 Hier Anm. 13 und Aellen (s. Anm. 14) 160-162. 174. 180. 191 Taf. 142-143.

17 LIMC I (1981) 302f. s. v. Agnoia Nr. 2 (F. Canciani); S. Gabra - E. Drioton, Peinures à fresque et scènes peintes à Hermoupolis-Ouest, Touna El-Gebel.(Kairo 1954) Taf. 15.

18 Zur Münchner Kopie und den historischen Hintergründen vgl. B. Vierneisel-Schlörb, Klassische Skulpturen des 5. und 4. Jabrhunderts v. Chr. (München 1979) 255-274 Abb. 119-127.

19 Zum Problem Verf., Der Logos des Mythos. Allegorien und Personifikationen in der früben griechischen Kunst (München 2001), bes. 82-95.

20 Verf. (s. Anm. 19) 190-208; dies., Eunomia oder: Vom Eros der Hellenen, in: R. von den Hoff - St. Schmidt (Hgg.), Konstruktionen von Wirklichkeit. Bilder im Griechenland des 5. und 4. Jabrhunderts v. Chr. (Stuttgart 2001) 299-314. 


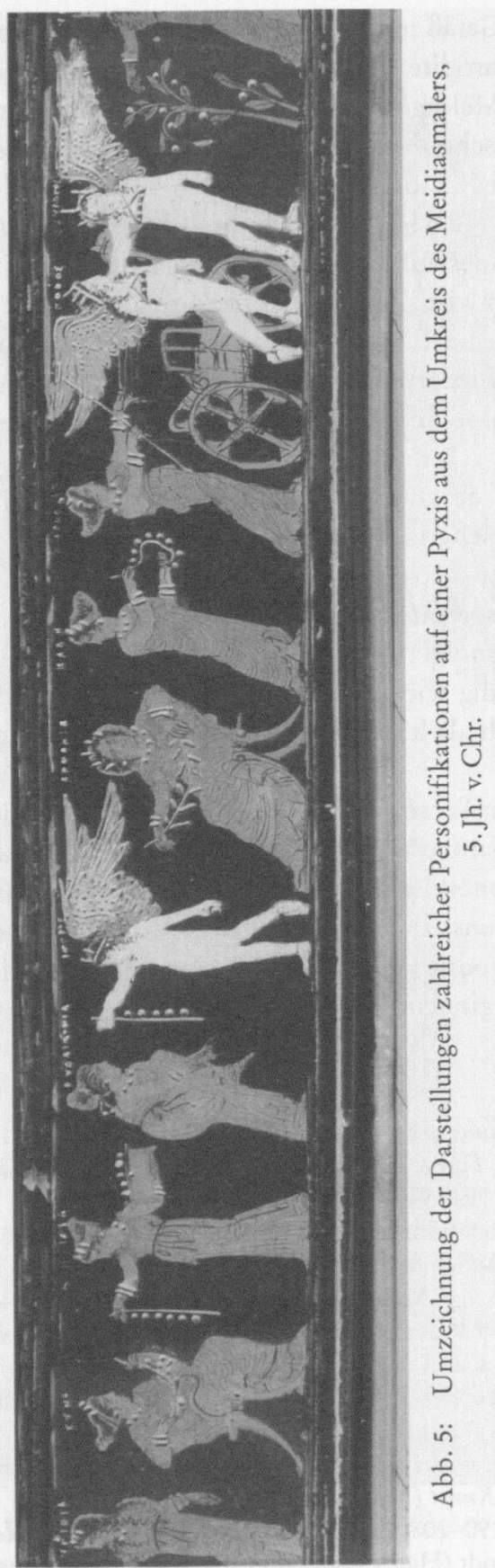


Paidia, das Spiel, eine Kette überreicht; daneben Eudaimonia, das Glück, zusammen mit Himeros, dem Verlangen; es folgt die wiederum sitzende Harmonia, dann eine Frau mit dem sprechenden Namen Kale, die Schöne, vor ihr Aphrodite, welche gerade einen Wagen besteigt, der von Pothos, der Begierde, und Hedylogos, den süßen Reden, gezogen wird, und schließlich Hygieia, die Gesundheit. Wie bei anderer Gelegenheit ausführlich gezeigt, lassen sich diese Bilder als Allegorien auf das Ideal maßvoller Liebe und sinnlicher Lust lesen, das als ebenso erstrebenswertes wie schwer erreichbares Lebensziel in so vielen Textgenres verhandelt wird. ${ }^{21}$ Doch so aufregend die Entdeckung komplexerer allegorischer Bilder in dieser Epoche ist, so eklatant ist auch der Unterschied zur Diabole. Während die Gestalten dort durch Physiognomie, Gesichtsausdruck, Handlung und Kleidung ausführlich charakterisiert sind, sind die Figuren auf der Pyxis und verwandten Gefäßen äußerlich ebenso wenig von einander zu unterscheiden, wie von anonymen Figuren und Göttern, und der narrative Gehalt der Darstellung ist denkbar gering. Es wird keine eigene Ikonographie mit spezifischer Bedeutung entwickelt, auch führen die Personifikationen keine sie in besonderer Weise charakterisierenden Handlungen durch, sondern bekannte Bildschemata werden allein durch Beischriften umgedeutet. ${ }^{22}$

Dasselbe gilt für das sog. Archelaos-Relief aus dem mittleren 2.Jh. v. Chr., das am Fuße eines Musenberges die Verehrung Homers durch die Personifikationen der Literaturgattungen im Beisein von Ilias und Odyssee, Arete, der Tugend, Mneme, der Erinnerung, Pistis, der Treue, und weiteren zeigt (Abb. 6). ${ }^{23}$ Ikonographisch unterscheidet sich die Darstellung wiederum kaum von zahlreichen Weihereliefs mit anonymen Adoranten. ${ }^{24}$ Sie verwendet dieselben Darstellungsschemata und die meisten Figuren sind äußerlich von menschlichen Adoranten nicht zu unterscheiden. Tragodia und Komodia tragen die Masken ihrer Genres

21 Ebd. u. a. zur Pyxis in London, British Museum E 775.

22 Im Bild des Aphroditewagens ist immerhin das Verhältnis der Göttin zu den Personifikationen allegorisch visualisiert, das Wesen der Gestalten ergibt sich jedoch allein aus ihren Namen. Entsprechend zieht Shapiro (s. Anm. 4) dieses Bild auch nicht zum Vergleich für die Diabole heran und stellt für verwandte Vasenbilder mit Recht nur ein allgemeines Interesse an allegorischer Ausdrucksform, nicht aber eine echte Entsprechung zur Diabole fest. Etwas anders beurteilt er die Darstellung auf einem Epinetron des Eretria Malers in Athen, NM 1629, weil sie einen gewissen narrativen Gehalt besitze. Doch ist dieser auch hier denkbar gering und die Ikonographie der Personifikationen ist wiederum völlig unspezifisch; s. Verf., Logos des Mythos (s. Anm. 19) 76-79.

23 D. Pinkwart, Das Relief des Archelaos von Priene, Antike Plastik 4, 1965, 55-65.

24 S. z. B. die Zusammenstellungen in U. Hausmann, Griechische Weihereliefs (Berlin 1960); G. Güntner, Göttervereine und Götterversammlungen auf attischen Weibreliefs (Würzburg 1988). 


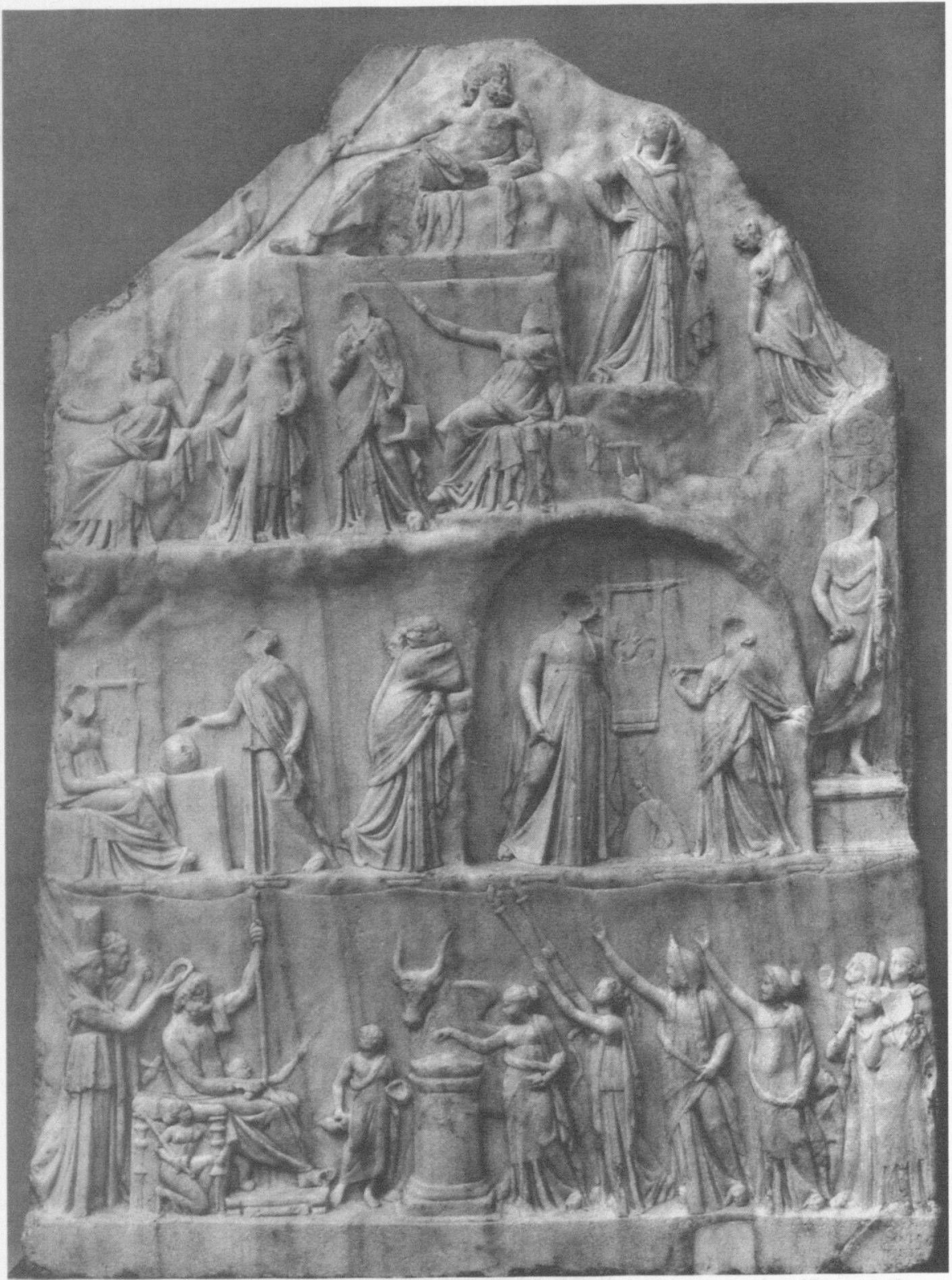

Abb. 6: Weiherelief des Archelaos von Priene mit Darstellung des Musenberges und der Verehrung Homers, 2. Hälfte 2. Jh. v. Chr. 
und sind dadurch auch visuell individualisiert. Doch handelt es sich hier nicht einmal um allegorische Attribute, sondern die beiden Personifikationen sind lediglich der Schauspielerikonographie angeglichen.

Hinsichtlich der Häufung metaphorischer ikonographischer Elemente und der Komplexität der ins Bild gesetzten abstrakten Aussage ist vielleicht der berühmte Kairos des Lysipp, die statuarische Darstellung des Günstigen Augenblicks oder der Gelegenbeit, die nächste Parallele zum Bild der Diabole. Doch ist andererseits gerade die Überlieferung dieser Figur kaum geeignet, das Vertrauen in die Zuverlässigkeit literarischer Ekphraseis zu stärken. Keine der insgesamt sieben literarischen Beschreibungen entspricht auch nur einer anderen genau, so dass man seit jeher über das ursprüngliche Aussehen des lysippischen Originals streitet. ${ }^{25}$ In diesem Falle ist die Lösung $\mathrm{m}$. E. ebenso einfach wie ernüchternd und liegt in der bildlichen, nicht in der schriftlichen Überlieferung: Drei Reliefs bzw. Relieffragmente (Abb. 7) ${ }^{26}$ zeigen einen Knaben im Ephebenalter mit großen Rückenflügeln, dessen Haar vorne lang, hinten aber geschoren ist. Er bewegt sich mit geflügelten Füßen voran, wobei er in der Rechten auf einem Schermesser eine Balkenwaage balanciert. Aus antiken Redewendungen und den literarischen Quellen ergibt sich die metaphorische Bedeutung der seltsamen Ikonographie. Am langen Haar kann man die Gelegenheit beim Schopfe fassen, wenn sie sich nähert, der kahle Hinterkopf vereitelt jedoch den Zugriff, wenn sie einmal vorübergeeilt ist. Die Flügel verdeutlichen die Geschwindigkeit, mit der dies geschieht, während die Waage wohl den Wechsel des Schicksals symbolisiert und das Schermesser den bereits seit Homer bekannten Ausdruck 'auf Messers Schneide' ins Bild setzt. Die drei Reliefs stehen untereinander im Replikenverhältnis, obwohl sie verschiedener Zeitstellung und an weit voneinander entfernten Orten gefunden sind, und müssen daher auf dasselbe Original zurückgehen. Will man nicht annehmen, eine spätere Variante der lysippischen Statue sei öfter kopiert worden als ihr berühmtes Vorbild, so können die Reliefs nur diese lysippische Figur wiedergeben. Die Ikonographien der literarischen Ekphraseis weichen jedoch alle von der tatsächlichen Ikonographie der Figur ab und stimmen auch untereinander nicht überein. Sie

25 A. F. Stewart, Lysippian Studies 1 . The Only Creator of Beauty, American Journal of Archaeology 82, 1978, 163-171; S. P. Kershaw, Personification in the Hellenistic World (British Thesis 1986) 3/1-3/63; P. Moreno, Testimonianze per la teoria artistic di Lisippo (Rom 1973) 73-79; 177-184; ders., Vita e Arte di Lisippo (Mailand 1987) 265-270; K. Moser von Filseck, Der Apoxyomenos des Lysipp und das Phänomen von Zeit und Raum in der Plastik des 5. und 4.Jhs. v. Chr. (Bonn 1988) 167f.; dies., Kairos und Eros (Bonn 1990) passim; LIMC V. (1990) 920-926 s.v. Kairos (P. Moreno); Altekamp (s. Anm. 4) 138-141; Verf., Logos des Mythos (s. Anm. 19) 85-88.

26 Turin, Mus. Arch. o. Inv.; Trogir, Monastero delle Benedettine o. Inv.; Athen, Akropolismus. 2799: LIMC V (1990) 922 s.v. Kairos Nr. 2-4 (P. Moreno); Verf. (s. Anm. 19) 85-88 mit Abb. 9-11. 


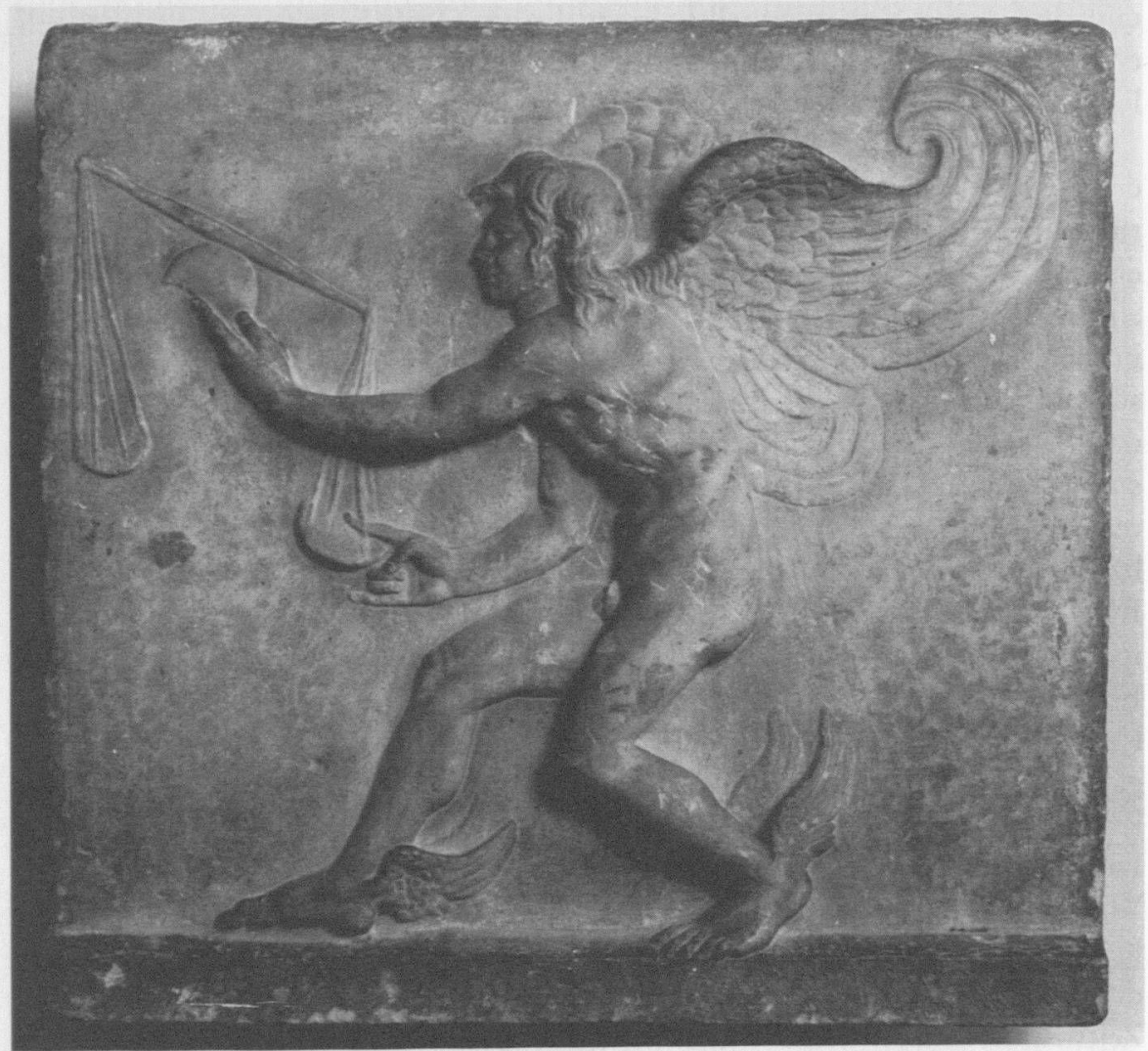

Abb. 7: Reliefdarstellung des Kairos des Lysipp, kaiserzeitlich.

stellen daher offensichtlich eine kreative und eminent literarische Auseinandersetzung mit diesem anregenden Bildentwurf dar. Dies gilt bereits für die älteste und der Skulptur zeitlich am nächsten stehende Beschreibung des Kairos durch Poseidipp, einen Dichter des 3. Jhs. v. Chr. Er wählte für sein Epigramm (Anthologia Palatina 16, 275) die Form eines Zwiegespräches zwischen der Statue, welche sich selbst erklärt, und ihrem Betrachter, welcher die Fragen stellt, aus denen wir das Aussehen der Skulptur erfahren:

Wo ist der Künstler zu Haus? - In Sikyon wohnt er. - Sein Name? - Ist Lysippos. - Du bist? - Gott des allmächtgen Moments. - Sag, warum gehst du auf Zehen? - Ich laufe beständig. - Weswegen hast du Flügel am Fuß? - Weil ich so flink bin wie Wind. - Und du hältst in der Rechten ein Messer? - Es kündet den Menschen: nichts in der Weite der Welt schneidet so scharf wir ich selbst. - Und das Haar an der Stirn? Beim Zeus, der Begegnende soll mich schnellstens erhaschen. - Warum bist Du denn hinten so kahl? - Bin ich mit fliegendem Fuß erst einmal vorübergeglitten, hält mich, so sehr 
man es wünscht, keiner von hinten mehr fest. - Und warum schuf dich der Künstler? Für euch! Und zu eurer Belehrung stellt er, Wandrer, mich auch hier in der Vorhalle auf. (Übersetzung H. Beckby)

Abweichend von den Reliefdarstellungen hält der Kairos hier jedoch das Messer in der rechten Hand. Die darauf balancierte Balkenwaage der Reliefs fehlt bei Poseidipp ebenso wie die Rückenflügel, den Reliefs dagegen fehlt der Zehenspitzenlauf.

Die ausführlichste Beschreibung findet sich bei Kallistratos, der, wohl im (späten) 4. oder frühen 5.Jh. n. Chr., eine Reihe von Ekphraseis antiker Kunstwerke verfasste. ${ }^{27}$ Auf den ersten Blick scheint er tatsächlich Beschreibungen zu liefern, wie das Herz des Kunsthistorikers sie begehrt. So erfahren wir gleich zu Beginn der sechsten Ekphrasis, dass Kallistratos den Kairos des Lysipp beschreiben wird, den der Künstler für die Sikyonier aufgestellt habe. Es folgt die Angabe des Materials, Bronze, und dann die eigentliche Beschreibung eines nackten Knaben in der Blüte seiner Jugend mit langem, wehendem Stirnhaar, am Hinterkopf aber nur Stoppeln, der mit geflügelten Füßen auf Zehenspitzen auf einer Kugel steht. Ausführlich wird seine Schönheit gerühmt und die Lebendigkeit der Darstellung, welche den Eindruck vermittelt, man sähe das Leuchten seiner Wangen und er könnte im nächsten Augenblick davonfliegen. Schließlich erscheint ein Erklärer, der den staunenden Betrachtern die Figur deutet als Lehre über die Blüte der Jugend selbst, welche jener niemals wiederkehrende günstige Augenblick sei, den es zu nutzen gälte.

Kallistratos hat sein Ziel wahrlich mehr als erreicht. Während er die Mehrzahl der Forscher überzeugt hat, der lysippische Kairos - oder jedenfalls eine Replik desselben - habe tatsächlich vor Lysipps Haus in Sikyon gestanden, schließen einige aus diesem Umstand sogar, der Kairos sei das künstlerische Manifest des Bildhauers gewesen - und zwar mit einem Tenor, der Lessing alle Ehre gemacht hätte: Lysipp habe jenen fruchtbaren Augenblick gemeint, den ein bildender Künstler finden muss, um trotz der Grenzen seines Genres, welches ja immer nur einen Moment, aber niemals ein in der Zeit sich entwickelndes Geschehen festhalten kann, dennoch ein solches Geschehen im Geiste des Betrachters heraufzubeschwören. ${ }^{28}$ Ein Autor meint gar, in der Beschreibung des Kallistratos den künstlerischen Stil des fortgeschrittenen 4. Jhs. v. Chr. und insbesondere des Lysipp wiederzuerkennen. ${ }^{29} \mathrm{Er}$ übersieht dabei nicht nur den topischen Charakter,

$27 \mathrm{Zu}$ Werk und Datierung s. Altekamp (s. Anm. 4) 77-154 mit der älteren Lit.

28 J. Dörig, The Late Classical Period 400-323 B.C., in: J. Boardman et al., The Art and Architecture of Ancient Greece (London 1967) 447; Stewart (s. Anm. 25); Moreno, Vita e Arte (s. Anm. 25) 265-270; Moser von Filseck, Apoxyomenos (s. Anm. 25) 167f.; dies., Kairos und Eros (s. Anm. 25) passim. Kritisch Altekamp (s. Anm. 4) $147 \mathrm{f}$.

29 Kershaw (s. Anm. 25) 3/48, obwohl er andererseits bezweifelt, dass Kallistratos das lysippische Original kannte. 
den der Preis der Lebensnähe von Kunstwerken seit Homer besitzt und den die hellenistischen Dichter, welche Kallistratos offenbar sorgfältig studiert hat, auf immer neue Weise variieren, sondern er bemerkt auch nicht die enge Übereinstimmung der vermeintlichen stilistischen Beschreibung des Kairos mit vielen der übrigen Ekphraseis des Autors. ${ }^{30}$ Die offensichtlichen Unterschiede zwischen der Ikonographie des kallistrateischen Kairos und den Reliefs - um von den übrigen literarischen Zeugnissen zu schweigen - werden bei all diesen Deutungen völlig ignoriert. Dabei gibt es bei Kallistratos kein Messer, keine Waage, keine Rückenflügel, stattdessen aber eine Kugel, auf der die Figur steht. Angesichts der genannten ikonographischen Abweichungen dürfte zudem eine gesunde Skepsis auch hinsichtlich der Angabe des Aufstellungsortes - und damit der aus diesem gefolgerten Bedeutung des Werkes - angebracht sein, denn welcher Ort wäre bei einem sikyonischen Künstler im Zweifelsfalle naheliegender gewesen als Sikyon? ${ }^{31}$

Dass es sich bei diesen Ekphraseis um ein innerliterarisches Spiel handelt, das bestenfalls anlässlich einer berühmten Figur betrieben wird, mag am deutlichsten das 33. Epigramm des Ausonius zeigen, eines lateinischen Rhetors aus dem 4. Jh. n. Chr. Wie Poseidipp wählt er die Form des Dialogs, bildet seine Statue der Occasio nun aber konsequenterweise weiblich. Mit Paenitentia, der Reue, die auf die verpasste Gelegenheit folgt, wird sie zu einer Gruppe erweitert, die er dem Phidias zuschreibt - als drittes Meisterwerk neben dessen Athena Parthenos und

30 Zum Topos der Lebensnähe in der hellenistischen ekphrastischen Dichtung s. Verf., Literarische Ekphrasis und künstlerischer Realismus, in: M. Büchsel - P. Schmidt (Hgg.), Realität und Projektion. Wirklicbkeitsnabe Darstellung in Antike und Mittelalter, Kolloquium Frankfurt 8.-10. November 2002 (im Druck); zu diesem Topos bei Kallistratos s. Altekamp (s. Anm. 4) bes. 86-89. 104-106.

31 Die Angabe ließe sich auch auf das Epigramm des Poseidipp zurückführen, in dem nämlich zu Anfang Sikyon als Heimatort Lysipps genannt wird und am Ende als Aufstellungsort der Skulptur év roơvígoı . Bei Poseidipp, der ja ein Zwiegespräch mit der Statue selbst und daher am Aufstellungsort imaginiert, kann allerdings eine Aufstellung im Haus des Lysipp kaum gemeint sein, denn dann wäre die erste Frage mit ihrer Antwort unverständlich. Anders Altekamp (s. Anm. 4) 90, der außerdem meint, Kallistratos habe die sikyonische Figur an ihrem späteren Aufstellungsort in Konstantinopel selbst gesehen (ebd. 96. 141). Die Argumentation wird hier jedoch zirkulär, denn die Abweichungen der Beschreibung von der tatsächlichen Ikonographie der Skulptur werden durch den Hinweis auf mögliche Beschädigungen im Verlauf der Jahrhundert und eine neue Aufstellung in Konstantinopel hinwegdiskutiert, um dann wiederum Kallistratos als wichtigsten Zeugen des Aussehens der Skulptur zu behaupten. Tatsächlich ist jedoch weder Kallistratos' Aufenthalt in Konstantinopel wirklich gesichert, noch eine Aufstellung des lysippischen Kairos ebenda. Die einzige Nachricht, auf die sich die Annahme stützen kann, Kedrenos, Synopsis bistorion 322c, stammt aus dem 11.Jh. und ist wenig verlässlich (dazu s. Ch. Blinkenberg, Knidia [Kopenhagen 1933] 32-35). 
Zeus von Olympia. Die Ikonographie wird leicht verändert und teilweise umgedeutet. Nach einer Selbsterklärung der Paenitentia, für die bezeichnenderweise keine eigene Ikonographie erfunden wird, schließt das Epigramm mit einer ironischen Wendung, indem Occasio bemerkt, der Betrachter jedenfalls habe während der ganzen Fragerei die günstige Gelegenheit verpasst. Auch wenn, soweit ich sehe, niemand sich dazu verstiegen hat, das Euvre des Phidias um diese Gruppe zu erweitern, ${ }^{32}$ so scheint mir doch auch die übliche Schlussfolgerung, Ausonius habe eine römische Umbildung der lysippischen Skulptur beschrieben, mehr als fraglich. ${ }^{33}$ Das Epigramm reagiert offensichtlich auf literarische Vorbilder, die es zu übertreffen sucht, nicht zuletzt durch die Zuschreibung an einen Künstler, der unbestritten als der größte der klassischen Antike galt.

Der Exkurs zur Überlieferung des lysippischen Kairos lehrt, dass der Umgang mit Bildern in literarischen Werken offenbar selbst dann sehr frei und eigengesetzlich war, wenn diese Bilder tatsächlich existierten. Müsste dies aber nicht zu umso größerer Vorsicht mahnen, wenn ein Werk nur ein einziges Mal überliefert ist, wie die Diabole des Apelles?

Kommen wir auf diese und auf die Suche nach verwandten Darstellungen noch einmal zurück. Zumindest die drei Reliefrepliken des Kairos geben Zeugnis von der tatsächlichen Existenz einer komplexeren antiken Figur allegorischen Charakters. Und doch steht diese den Tychen mit ihren Steuerrudern oder den Eroten mit ihren Bogen, von denen sie sich hauptsächlich durch die Anzahl der Attribute unterscheidet, näher als der vielfigurigen, ausführlich erzählenden Allegorie des Lukian, deren Personal durch je eigene, seine Wesensart spiegelnde Ikonographien und Handlungen charakterisiert ist. Theoretisch könnte man den Bestand an erhaltenen oder sicher überlieferten antiken Bildern in dieser Weise weiter durchgehen und würde doch kein einziges Bild finden, das der Diabole entspräche. Entscheidend ist dabei, dass sich diese Entsprechung bzw. deren Fehlen nicht auf den Inhalt der Darstellung, das Thema - in diesem Falle Verleumdung -, und auch nicht auf die generelle Komposition bezieht, sondern auf strukturelle Eigenheiten der Visualisierung, auf die Art der Bildsprache, auf die Strategie der Vermittlung des Inhalts.

32 S. aber die erstaunlich vorsichtige Formulierung in LIMC VI (1992) $561 \mathrm{f}$. s.v. Metanoia (E. Polito): "probabilmente un errore di Ausonio o della sua fonte (meine Hervorhebung).

33 Die Existenz der Gruppe ohne weiteren Kommentar akzeptiert: Massing (s. Anm. 5) 21; LIMC VI (1992) 561 f. s. v. Metanoia (E. Polito); S. Settis, Immagini della meditazione, dell'incertezza e del pentimento nell'arte antica, Prospettiva 2, 1975, 4-18, bes. 14 mit Abb. 39, der eine Reliefdarstellung in der Kathedrale von Torcello für einen Reflex der originalen Skulptur, nicht des Ausonius-Epigramms zu halten scheint. Zur Überlieferung des Kairos bereitet Verf. einen eigenen Beitrag vor. 
Tatsächlich findet sich dasjenige antike Bild, das in dieser Hinsicht vielleicht als beste Parallele zur Diabole gelten kann, ebenfalls bei Lukian - und wieder nur bei diesem: ${ }^{34}$ das Bild eines Herakles-Ogmios (vgl. Abb. 8-9). In seiner Prolalia Hercules behauptet Lukian, einst in Gallien ein Bild gesehen zu haben, das einen Greis mit den Attributen des Herakles zeigte. Ihm folgte freudig eine Schar von Leuten, deren Ohren durch zarte, goldene und bernsteinene Ketten mit der Zungenspitze des Greises verbunden waren. Ich übergehe hier verschiedene Versuche, in der gallischen Bildkunst einen Herakles-Ogmios nachzuweisen, die heute, übrigens nach übereinstimmender Meinung, alle als gescheitert angesehen werden können. Dem Glauben an Lukians Bild hat dies jedoch keinen Abbruch getan. Vielmehr gilt es im größten Teilen der französischen Forschung und darüber hinaus als gesichert, dass das Bild existierte, und dass es weitreichende Schlüsse über das Wesen eines gallischen Gottes erlaube, ${ }^{35}$ dessen Name Ogmios sonst allerdings ausschließlich in zwei Fluchtäfelchen aus Gräbern in Bregenz nachgewiesen bzw. ergänzt ist. ${ }^{36}$ Dort soll er den magischen Bann über Körper und Vermögen der verfluchten Person bewirken. Weder ist hier jedoch eine Verbindung mit Herakles erkennbar, noch scheint Herakles in Gallien, wo er sich tatsächlich großer Beliebtheit erfreute, oder sonst irgendwo im römischen Reich je mit Eigenschaften ausgestattet worden zu sein, die denen des Ogmios der Fluchtäfelchen oder auch des lukianschen Bildes entsprächen. Als bester Beweis der Existenz des Bildes gilt daher vielen Lukians Geständnis seiner anfänglichen Verwirrung angesichts des Bildes: er habe sich die Befestigung der Ketten an der Zungenspitze des Ogmios zunächst damit erklärt, dass dieser keine $\mathrm{Hand}$ mehr frei gehabt habe; erst ein gallischer, glücklicherweise griechisch gebildeter Weiser, so beteuert er, habe ihm die Darstellung als Allegorie über die Macht der Rede im hohen Alter deuten können.

34 Darauf wies bereits Koepp (s. Anm. 3) 72f. hin, freilich mit anderen Schlussfolgerungen.

35 Ausführlich R. Egger, Aus der Unterwelt der Festlandkelten, Wiener Studien 35, 1943, 99-121; F. Le Roux, Le dieu celtiqe au liens. De l'Ogmios de Lucien à l'Ogmios de Dürer, Ogam 12, 1960, 209-234, bes. 213-215; J. Loic, Ogmios-Varuna et l'organisation de la fonction de souveraineté dans le panthéon celtique, in: Orientalia J. DuchesneGuillemin emerito oblata. Acta iranica. Hommages et opera minora 9 (Leiden 1984) 341-382; als keltisches Bild eines gallischen Herakles-Ogmios noch akzeptiert in LIMC V (1990) 256 Nr. 27; 261 f. s. v. Herakles/Hercules (in peripheria occidentali) (L. J. Balmaseda); F. Bader, Héraklès, Ogmios et les Sirènes, in: C. Jordain-Annequin C. Bonnet (Hgg.), Héraclès, les femmes et le féminin, IIe rencontre héracléenne, Actes du Colloque de Grenoble, 22-23 octobre 1992 (Brüssel/Rom 1996) 145-185. Zu den wenigen Skeptikern gehören Blümner (s. Anm. 2) 82 Anm. 1 und Varwig (s. Anm. 5) 44.

36 Egger (s. Anm. 35), bes. 103-108; mein herzlicher Dank gilt Andrea Scheithauer für wichtige Hinweise zu den Texten der Fluchtäfelchen. 


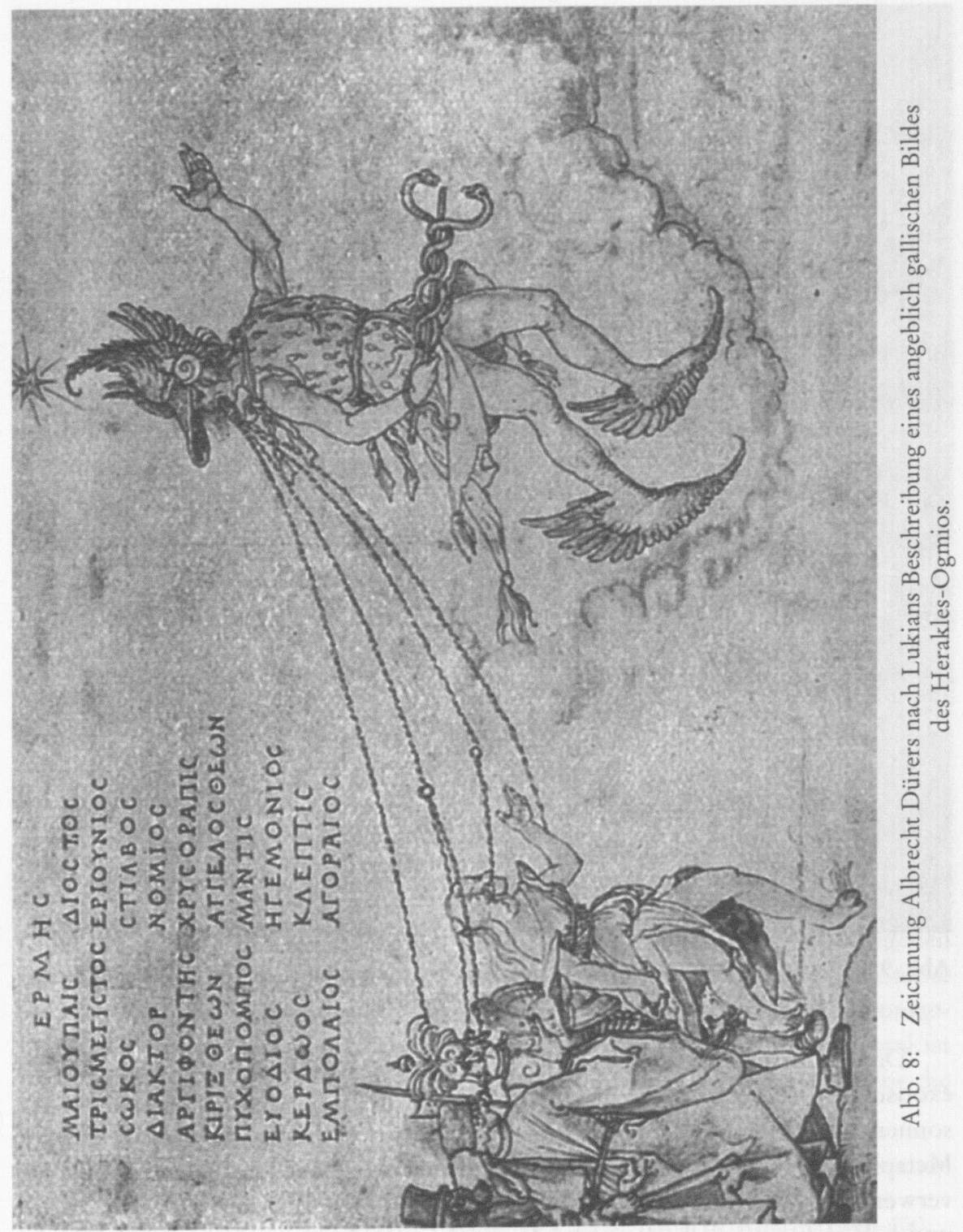




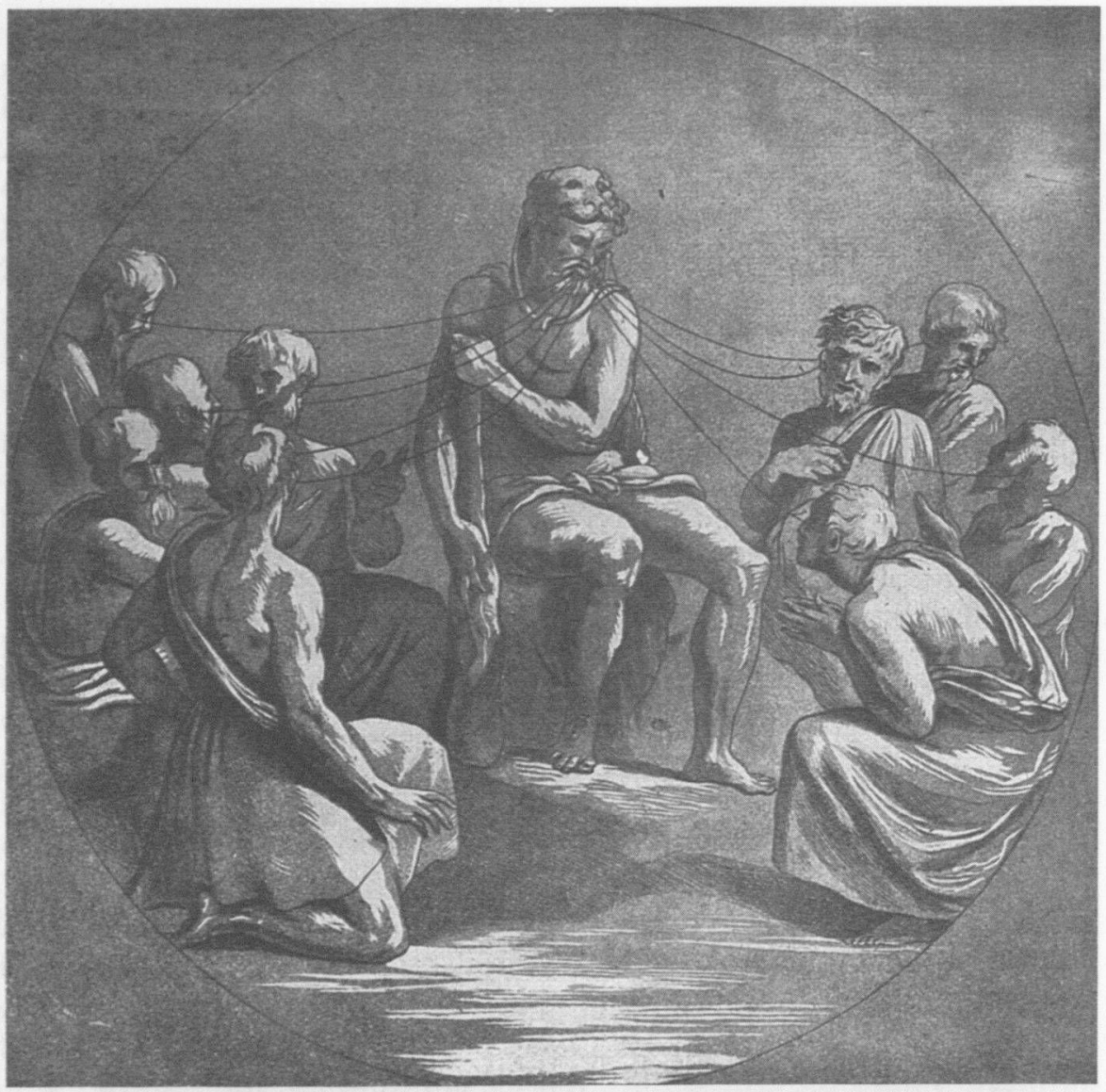

Abb. 9: Zeichnung Raffaels nach Lukians Beschreibung eines angeblich gallischen Bildes des Herakles-Ogmios.

Dass Lukians Naivität gespielt ist und seinen Zuhörern die Existenz des exotischen Bildes plausibler machen sollte, hat immerhin Jean Loicq in der besonnensten Behandlung der Ogmios-Problematik vermutet, da Lukian dieselbe Metapher der an den Ohren geführten Zuhörer auch in seinem Juppiter tragoedus verwendet. ${ }^{37}$ Und dennoch will auch Loicq nicht endgültig von dem Bild lassen, und hält es für möglich, dass es sich um eine von Lukian missverstandene oder umgedeutete Darstellung der magischen Bindekraft des Ogmios handelte. Theo-

37 Lucianus Juppiter tragoedus 45. Vgl. Loic (s. Anm. 35) 344, ähnlich G. Hafner, Herakles, Geras, Ogmios, Jabrbuch des Römisch-Germanischen Zentralmuseums Mainz 5 (1958) 139-153, hier 148. 
retisch wäre dies wohl nicht auszuschließen, aber wo wären dafür - abgesehen von der vollmundigen Behauptung Lukians - noch irgendwelche Anhaltspunkte? Die Einführung eines Erklärers ist durchaus topisch und verfolgt hier, indem dieser erklärt, was der Zuhörer ohnehin schon bemerkt hat oder zumindest ahnt, vor allem noch ein weiteres Ziel: Lukians Publikum einen intellektuellen Erfolg und das momentane Gefühl geistiger Überlegenheit zu gönnen. Es handelt sich um eine Grundstrategie der Prolaliai, der Einleitungsreden, zu denen auch der Hercules gehört, welche eine freundliche Atmosphäre der Solidarität zwischen dem Redner und seinem Auditorium schaffen sollen. ${ }^{38}$ De electro zeigt dies besonders schön. Hier erzählt Lukian u.a., wie er einst voller Naivität an den Mythos über Phaeton und die Heliaden glaubte, welche, in Pappeln verwandelt, Tränen aus Bernstein vergössen. Um diesen Bernstein zu sammeln und schnell zu Reichtum zu gelangen, sei er zum Po, der mit dem mythischen Fluß Eridanos gleichgesetzt wurde, gereist, wo seine Hoffnungen jedoch von seinen Ruderleuten zunichte gemacht wurden: Diese waren zwar schlichte Gesellen ohne Bildung, erwiesen sich am Ende aber als ihrem Kunden an Schläue und Realitätssinn deutlich überlegen. Diese Strategie der Etablierung einer ironischen Komplizenschaft zwischen Rhetor und Publikum, bei der es auf die Faktizität der erzählten Geschichte offenbar nicht ankam, ist allerdings im Falle des Hercules bei den modernen Lesern so gründlich fehlgeschlagen, dass sie selbst in jüngeren Untersuchungen nicht bemerkt wird.

Wie im Falle der Diabole, so sucht man auch im Falle des Herakles-Ogmios vergeblich nach vergleichbaren Darstellungen - und in diesem Fall gilt dies sogar für die Komposition und für Grundelemente der Ikonographie. ${ }^{39}$ Dagegen fehlt jede Parallele für ein vielfiguriges Bild, in dem sowohl die zentrale Handlung als auch nahezu jedes ikonographische Detail metaphorisch zu deuten ist. HeraklesOgmios ist alt, weil es Lukian um die Redekunst des Alters (seines eigenen Lebensabschnitts) geht. Er ist ein Herakles, weil Herakles der Inbegriff der Stärke und des überlegenen Helden ist. Dessen eigentlich physische Kraft wird umgedeutet und auf die Redekunst übertragen, wo sie jedoch ebenso bezwingend ist wie üblicherweise seine Körperkraft: ${ }^{40}$ dies verdeutlichen die Ketten, welche die

38 H. G. Nesselrath, Lucian's Introductions, in: D. R. Russell (Hg.), Antonine Literature (Oxford 1990) 111-140.

39 Dies bereits anerkannt von Koepp (s. Anm. 3), s. auch Hafner (s. Anm. 37) 144-150.

40 Diesen Punkt übersieht Hafner (s. Anm. 37) 149-153, wenn er in der Ikonographie komische Züge erkennt und die Darstellung auf eine angeblich seit dem 5. Jh. v. Chr. bekannte burleske Geschichte um Herakles und Geras bezieht, aus der Geras nach Hafner zwar als Sieger hervorgeht, aber dennoch eine lächerliche Figur bleibt, wie die Ikonographie der übrigen von Hafner mit der Geschichte verbundenen Darstellungen belegt. Dies würde jedoch der rhetorischen Absicht Lukians entgegenstehen. Zu Hafners These s. auch Verf., Logos des Mythos (s. Anm. 19) 88-94. 
Anhänger des Herakles binden. Da sie von der Zunge des Helden zu ihren Ohren verlaufen, sind aber auch sie nicht konkret zu verstehen, sondern als Bild für die Bindekraft der Rede, welche aus dem Mund des Herakles die Ohren seiner Zuhörer erreicht. Aus diesem Grund sind sie auch nicht aus reißfestem Material, sondern kostbar und zart, aus Gold und Bernstein, und die so Gefesselten folgen freudig. Dabei geben sich einige der allegorischen Motive als direkte bildliche Umsetzungen literarischer metaphorischer Ausdrucksweisen zu erkennen, wie die durchbohrte Zunge ${ }^{41}$ und die Pfeile des Herakles als Sinnbild der 'geflügelten Worte' Homers. ${ }^{42}$ Wollte man aus diesem komplexen allegorischen Bild mit denjenigen, die aus Lukians Beschreibung das 'wahre' Originalbild herauslösen möchten, die allegorischen Elemente auf ein Maß reduzieren, welches tatsächlich Parallelen in der antiken Kunst besitzt, so bliebe von Lukians Beschreibung kaum etwas übrig. Und was wäre diese dann für einen Archäologen noch wert?

Alle diese Überlegungen sind zweifellos nicht geeignet, die Existenz des Herakles-Ogmios oder der Diabole zwingend zu widerlegen - dies liegt in der Natur der Problematik. Doch sind sie durchaus geeignet, erhebliche Zweifel zu wecken. Kein einziges erhaltenes oder sicher überliefertes antikes Bild bedient sich derselben komplexen allegorischen Rhetorik wie diese beiden Gemälde, besitzt dieselben strukturellen Eigenheiten der Vermittlung ihres Sinns. Der einzige Meister, dessen Stil die Bilder tatsächlich entsprechen, ist Lukian selbst, durch dessen gesamtes Werk sich zwei Motive ziehen: seine außergewöhnliche Vorliebe für Personifikationen und Personifikationsallegorien und der Wettstreit der Künste.

Der erste Punkt ergibt sich leicht durch einen Blick in die Gesamtausgabe seiner Werke. In vielen Dialogen stellen Personifikationen einen Teil, gelegentlich den überwiegenden Teil des Personals: etwa Wahrheit, Tugend, Syllogismus oder die Überführung im Piscator, oder Gerechtigkeit, Akademie, Stoa, Tugend, Üppigkeit, Rhetorik und der Dialog im Bis accusatus.

Der Wettstreit der Künste ist das Grundthema der Beschreibung des Schönen Saals in De domo, und der Panthea in Imagines. ${ }^{43}$ In De domo behauptet die

41 Kock, Comicorum Atticorum Fragmenta, adesp. 398 = Poetae Comici Graeci VIII 457, Hafner (s. Anm. 37) 144.

42 Der allegorische Charakter der Ikonographie bereits anerkannt von Koepp (s. Anm. 3), bes. 69-73, der jedoch die Diabole als Beweis für die Existenz solcher Bilder in der Antike nimmt.

43 S. aber auch Herodot oder Aëtion, wo die Erfolge des Historikers (und seiner Schrift) denen des Malers gegenüber gestellt werden. In der Regel wird, besonders mit Hinweis auf seine (angeblich) autobiographische Erzählung in Somnium, Lukians besondere Kenntnis und Wertschätzung der bildenden Kunst betont. Das ist zweifellos richtig, unterschätzt jedoch den Aspekt des Wettstreits, der mir hier zentral zu sein scheint. 
Personifikation des Logos explizit, Worte könnten niemals so wirkungsvoll sein wie der Anblick eines schönen Gegenstandes, in diesem Falle des gepriesenen Saales - weshalb Logos seinen Gegner im Rededuell konsequenterweise durch eine Beschreibung des Saals und somit durch die Steigerung der visuellen Eindrücke besiegt, anstatt wie dieser sein Lob in mehr oder weniger gelehrte Anekdoten und Vergleiche zu kleiden. Man darf sich durchaus fragen, ob Lukian seine Rede tatsächlich in dem beschriebenen Saal gehalten hat, wie oft vermutet wurde, ${ }^{44}$ oder ob er nicht in einer ironischen Volte die Bescheidenheit seiner Rede indirekt dadurch widerlegte, dass er den Zuhörern allein kraft dieser Rede einen Saal vor Augen stellte, der in Wahrheit nicht existierte. In jedem Fall stellt sich dieser Effekt für den Leser seiner Rede ein.

Imagines ist ein Panegyricus auf Panthea, die Geliebte des Kaisers Lucius Verus. Deren unvergleichliche Schönheit wird evoziert durch die Beschreibung und rhetorische Verbindung der schönsten Teile der schönsten antiken Skulpturen, der Athena Lemnia des Phidias, Alkamenes' Aphrodite in den Gärten, Praxiteles' Aphrodite von Knidos und der Sosandra des Kalamis, sowie der Farben der berühmtesten Maler, Euphranor, Polygnot, Apelles und Aëtion. Lukian imitiert und invertiert damit ein Verfahren, das der Maler Zeuxis der bekannten Anekdote zufolge anwandte, als er das Bild der Helena durch ein eklektisches Porträt der jeweils schönsten Körperteile der schönsten krotoniatischen Jungfrauen schuf. ${ }^{45}$ Lukian vergleicht sich demnach mit diesem vielgerühmten Künstler: Indem er sich aus dem Formenrepertoire der schönsten Skulpturen der antiken Welt bedient, beweist er seine Kennerschaft; darüber hinaus behauptet er aber nicht nur, Panthea und ihre Schönheit überträfen jede einzelne dieser Figuren, sondern er behauptet dasselbe implizit auch von seinem eigenen Werk: Er übertrifft mit seinen rhetorischen Künsten all die berühmten Maler und Bildhauer, die diese Kunstwerke geschaffen haben, und die implizit als in Bezug auf die Schönheit defizient entlarvt werden.

Andere Texte Lukians verbinden beide Motive, die Allegorie und den Wettstreit der Künste. In seinem Rhetorum praeceptor nimmt er sich ausdrücklich die, übrigens noch ein zweites mal erwähnte, Tabula Cebetis, ein fiktives Bild, das in einer Art Miniaturausgabe der Divina Comedia mit Dutzenden von Personifikationen den Lebensweg des Menschen darstellt, zum Vorbild seines eigenen allegorischen Bildes. Sein Gemälde stellt den Weg zum Erlernen der Rhetorik dar und

44 Z. B. Bompaire, Lucien écrivain (s. Anm. 4).

45 Plin. NH 35, 64; Cicero, De inventione 2, 1, 1-3; Dionysius Halicarnassensis, De imitatione fr. 6, 417. Anders K. Korus, The motif of Panthea in Lucian's encomium, Eos 69, 1981, 47-56, der die Vorgehensweise nicht auf die Zeuxis-Anekdote selbst, sondern auf die Aufforderung zu eklektischem Vorgehen durch Rhetoriklehrer wie Dionysios von Halikarnass beziehen möchte. 
löst sich später elegant in echte Handlung und Erzählung, die Wanderung des Rhetorikschülers und seines Lehrers, auf.46

Im Traum (Somnium sive Vita Luciani) schließlich wird der junge, nach einer geeigneten Beschäftigung suchende Lukian von den Personifikationen der Bildhauerkunst und der Paideia, der Bildung, umworben, für welche er sich am Ende entscheidet. Der Text ist Prodikos' Herakles am Scbeideweg nachgebildet und vereint die beiden Motive der Personifikationsallegorie und des Wettstreits der Künste in einer Art 'Gründungslegende' zu Lukians eigener Tätigkeit und Lebensaufgabe.

Kommen wir noch einmal auf die Diabole und den Herakles-Ogmios zurück: Ihr Erscheinen in den Reden Lukians entspricht nicht nur dessen Vorliebe für bestimmte Themen und Vermittlungsstrategien - diese könnte grundsätzlich auch eine entsprechende Auswahl aus dem Fundus existierender Bilder begründen. Entscheidend ist vielmehr, dass die Darstellungen zugleich hinsichtlich ihrer semantischen Struktur ohne Parallele im Bestand der erhaltenen oder sicher überlieferten Bilder sind, dagegen aber recht genau literarischen bzw. rhetorischen Verfahren entsprechen. Die ältesten Allegorien und Allegoresen finden wir bereits bei Homer - also lange vor den ersten allegorischen Bildern -, der im Übrigen in der Rede des Phoinix, welcher Achill wieder zur Teilnahme am Kampf um Troja überreden will, dieselben drei rhetorischen Strategien verbindet, die wir auch in Lukians Calumnia finden: eine allgemein gefasste Wahrheit (hier, dass man berechtigten Bitten gehorchen soll, dort die Gefahren von Neid und Verleumdung), die durch ein Beispiel (hier den Meleagermythos, dort u. a. die Erzählung der Verleumdung des Apelles bei Ptolemaios) und durch eine Allegorie (hier die Allegorie der Litai, dort das Gemälde der Diabole) belegt werden soll. ${ }^{47}$ Wir sind offensichtlich mit der befremdlichen Situation konfrontiert, dass eine Ausdrucksund Vermittlungsform, welche ihre Kraft und Eindrücklichkeit gerade aus der Imagination eines Bildes zieht, nämlich die komplexere Allegorie, ausgerechnet in Sprache entwickelt wird und in die reale Bildkunst erst ganz allmählich Eingang findet. ${ }^{48}$

46 Massing (s. Anm. 5) 19 mit Anm. 29; ähnlich geht er in De Mercede conductis potentium familiaribus 42 vor, wo die Beschreibung eines Gemäldes „in der Art des Kebes“

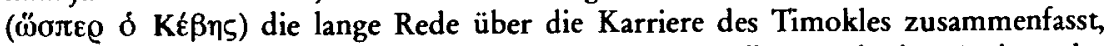
wobei das Vorgehen hier damit erklärt wird, dass ein Apelles, Parrhasios, Aëtion oder Euphranor nicht mehr zur Verfügung stünden, um ein solches Gemälde zu malen.

47 Vgl. hierzu Verf., Logos des Mythos (s. Anm. 19) passim, bes. 42-48 zu Homer und der Bittrede des Phoinix in $\mathrm{Il}$. 9, $434 \mathrm{ff}$.

48 Tatsächlich scheinen die vereinzelten Ausnahmen komplexerer Personifikationsallegorien durch literarische Vorlagen angeregt zu sein. Zwei Vasendarstellungen zeigen Dike (Recht/Gerechtigkeit), welche die mit Tätowierungen bzw. Körperbemalung versehene, hässliche Adikia (Unrecht/Ungerechtigkeit) stranguliert und mit einer Doppel- 
Aus den vorgetragenen Überlegungen dürfte ausreichend deutlich geworden sein, dass die Rekonstruktion antiker Kunstwerke aus literarischen Ekphraseis übrigens nicht nur des Lukian - eine mehr als heikle Angelegenheit ist. Es ließe sich ausführlicher zeigen - und wurde auch bereits vielfach gezeigt -, dass diese Ekphraseis zwar gelegentlich real existierende Kunstwerke zum Anlass nehmen, ihren Ehrgeiz aber nicht in eine möglichst exakte Beschreibung derselben legen, sondern in ein oftmals äußerst raffiniertes Spiel mit Sehen und Gesehenwerden, mit Sehen und Hören und nicht zuletzt mit der Realität bildlicher Darstellung und der Kunst rhetorischer enargeia, der Macht der Sprache, visuelle Bilder zu schaffen, den Zuhörer zum Zuschauer zu machen. ${ }^{49}$ Diesen Eindruck scheint nicht zuletzt der sechste Iambus des Kallimachos zu belegen, der für einen Freund des Dichters, welcher eine Reise nach Elis beabsichtigt, die Statue des phidiasischen Zeus beschreibt: Der Iambus ist leider nur fragmentarisch erhalten, doch scheint die Beschreibung mit keinem Wort auf die Darstellung selbst oder auf die Gesamtwirkung des Werkes einzugehen, also auf jene Aspekte, die sonst im Zentrum hellenistischer ekphrastischer Epigramme stehen. Sie scheint vielmehr ausschließlich aus technischen Angaben bestanden zu haben, über das Material, die Maße, das Gewicht, die Kosten usw. Zuletzt hat Arndt Kerkhecker ausführlich die Ironie der ganzen Beschreibung herausgearbeitet und den Iambus als Auseinandersetzung mit der für Ekphraseis geforderten enargeia gedeutet, deren Regeln der Iambus diametral entgegen steht. ${ }^{50}$

axt bedroht. Die außergewöhnlichen Bilder kopieren offenbar eine Szene auf der Kypseloslade, welche auch sonst zahlreiche ungewöhnliche Darstellungen aufwies, die sich nur durch eine enge Anlehnung an literarische Vorlagen bzw. literarische Verfahren erklären lassen; für eine ausführliche Argumentation s. Verf., Logos des Mythos (s. Anm. 19) 119-122; 135-141; 161-164. Die zweite Ausnahme ist ein verschollenes, von Gi. A. Dosio und G. Clovio gezeichnetes Relieffragment, das seiner Inschrift zufölge OI EIC TON BION EICIIOPEYOMENOI (die in das Leben hineingeführt werden) zeigte. Inschriftlich benannt sind Bios und Apate, eine weitere Figur dürfte Tyche sein. Bei dem Relief scheint es sich jedoch um eine - im Detail leicht abweichende und inhaltlich reduzierte - Illustration der Tabula Cebetis in der Art der Tabulae Iliacae zu handeln: K. K. Müller, Relieffragment mit Darstellungen aus dem MINA des Kebes, Archäologische Zeitschrift 42, 1884, 115-127; C. Robert ebd. 127f.; R. Schleier, Tabula Cebetis (Berlin 1973) 85f. Abb. 31-32. Im Falle der Diabole des Apelles und des Herakles-Ogmios soll es sich dagegen um originale Bildentwürfe handeln.

49 F. Graf, Ekphrasis: Die Entstehung der Gattung in der Antike, in: G. Boehm - H. Pfotenhauer (Hgg.), Beschreibungskunst - Kunstbeschreibung. Ekphrasis von der Antike bis zur Gegenwart (München 1995) 113-155.

50 A. Kerkhecker, Callimachus' Book of Iambi (Oxford 1999) 147-181; ders., Wieland und der Zeus des Phidias, in: J. P. Schwindt (Hg.), Tradition und Innovation. Poetische Verfabren im Spannungsfeld Klassischer und Neuerer Literatur und Literaturwissenschaft (München/Leipzig 2000) 135-162. 
Doch was bedeutet all dies für den Archäologen? Soll er - oder sie - frustriert das Feld räumen und die literarischen Ekphraseis wieder ganz den Philologen überlassen? Wenn die Faktizität des Behaupteten so offensichtlich Gegenstand eines Spiels, bestenfalls aber zweit- oder drittrangig ist, muss dann nicht die Rekonstruktion antiker Kunstwerke auf ihrer Grundlage aufgegeben werden? Vielleicht ist dies so, aber ohne Zweifel lassen sich die hier an einzelnen Beispielen gewonnenen Ergebnisse nicht bedenkenlos generalisieren - nicht einmal in Bezug auf Lukian. ${ }^{51}$ Vielleicht genügt es auch, mehr Vorsicht und Skepsis bei ihrer Auswertung walten zu lassen, wobei, wie deutlich geworden sein sollte, literaturund kunstkritische Ansätze miteinander zu verbinden wären. In einer Hinsicht können viele antike Ekphraseis jedoch durchaus der Rekonstruktion antiker Kunst dienen, wenn wir darunter nämlich nicht mehr allein deren physische Rekonstruktion verstehen, sondern deren Rekonstruktion im Wahrnehmen und Denken der antiken Betrachter von Bildern; nicht ihren musealen, statischen Charakter im Auge haben, sondern die verschiedenen Weisen, in denen sie rezipiert und weitergedacht werden konnten ${ }^{52}$ - ich erinnere an die Auseinandersetzung mit dem lysippischen Kairos und gebe noch ein weiteres Beispiel, mit dem wir wieder stärker in die Nähe Lukians rücken. Ein Dialog mit dem Titel Erotes, der unter dem Namen Lukians überliefert ist, diesem aber in der Forschung heute abgesprochen wird, ${ }^{53}$ ist ein philosophisches Gespräch über die jeweiligen Vorzüge homo- bzw. heterosexueller Liebe. Lykinos erzählt darin von einem Besuch im Aphrodite-Heiligtum von Knidos, den er einst zusammen mit dem Athener Kallikratides und dem Korinther Charikles machte. Als sie zu dem berühmten Tempel der Göttin mit der nicht minder berühmten Statue des Praxiteles (Abb. 10) kommen und Aphrodite gegenüber treten, bewundert Charikles ihre Schönheit und erotische Ausstrahlung über die Maßen. Um die Göttin auch von hinten betrachten zu können, gehen sie anschließend um den Tempel herum, wo ihnen von einer Schlüsselbewahrerin eine extra zu diesem Zweck eingerichtete weitere Tür geöffnet wird. Nun ist es an Kallikratides in Bewunderung über Aphrodites nicht minder erotische Rückseite auszubrechen, welche so schön sei wie die der

51 Ich verzichte hier auf eine ausführlichere Besprechung der übrigen von Lukian mehr oder weniger ausführlich beschriebenen Kunstwerke, da diese sich überwiegend erheblich besser in das bekannte Spektrum antiker Kunst fügen und sich daher durchaus auf reale Werke beziehen können, oder sogar nachweislich existiert haben; vgl. die Zusammenstellungen bei Blümner und Andò (s. Anm. 3) passim.

52 Elsner, Art and the Roman Viewer (s. Anm. 1) 21-48 mit einem solchen Versuch zur Tabula Cebetis und den Imagines des Philostrat.

53 C.P. Jones, Tarsos in the Amores ascribed to Lucian, Greek, Roman and Byzantine Studies 25, 1984, 177-181, mit Datierungsvorschlag in das späte 2. oder die erste Hälfte des 3.Jhs. n. Chr. 


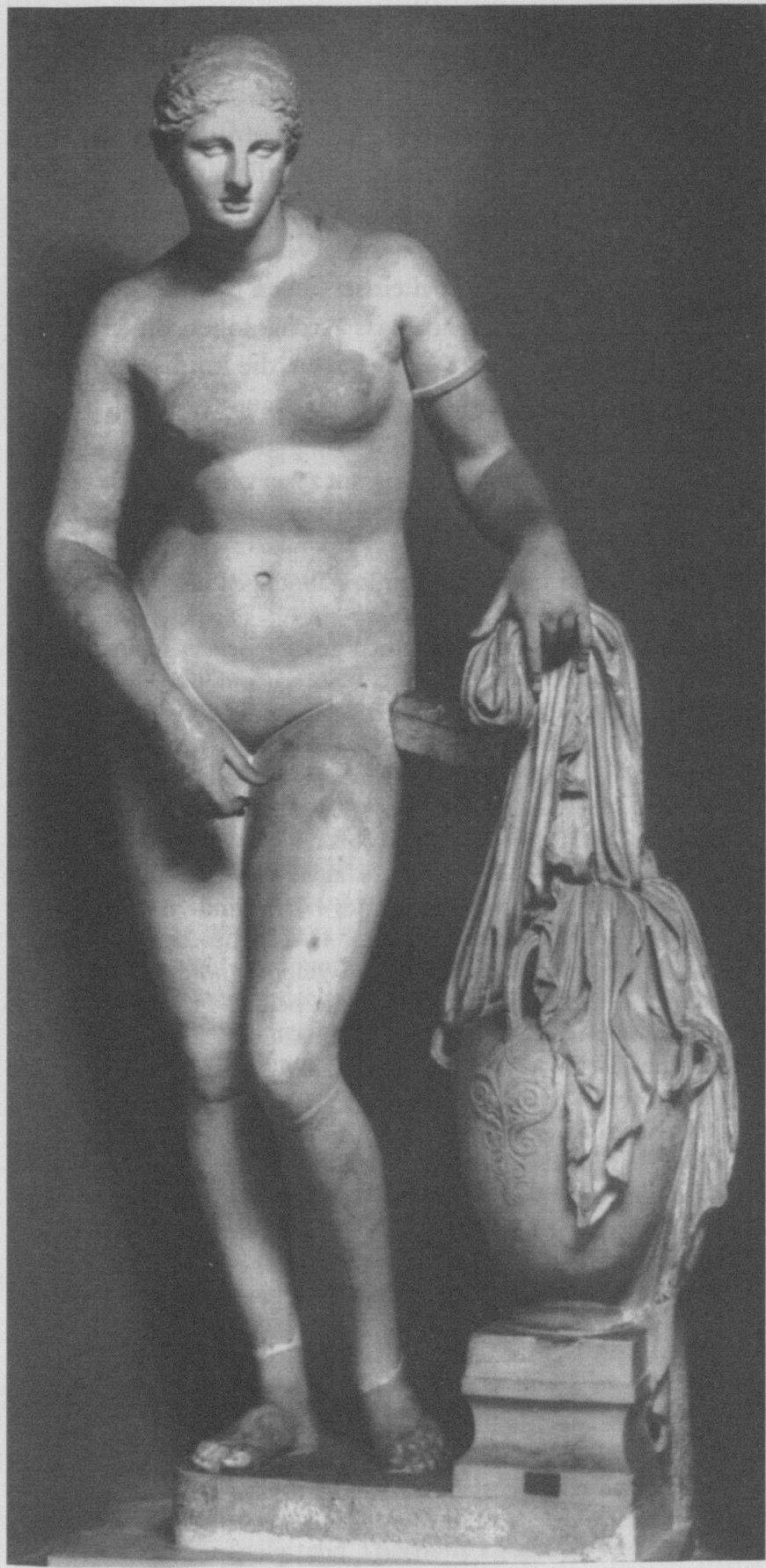

Abb. 10: Aphrodite von Knidos, römische Kopie im sog. Typus Colonna. 
schönsten Knaben und selbst des Ganymed. Wie die Priesterin erklärt, ist er jedoch nicht der erste, der von diesem Anblick entzückt ist: Ein Fleck auf dem Marmor sei das Relikt des amourösen Übergriffs eines verzweifelten Verliebten, der sich eines Nachts in den Tempel habe einschließen lassen und sich nach der Schändung der Statue von den Klippen gestürzt habe. Der Darstellung PseudoLukians zufolge stand die Aphrodite demnach in einem Tempel mit zwei einander gegenüberliegenden Türen, und eine geschlossene Cella verlangt auch die Anekdote mit dem Liebeskranken, der sich im Tempel einschließen lässt. ${ }^{54}$ Die literarische Schilderung war offenbar so überzeugend, dass Archäologen die erheblich lapidarer formulierte Angabe des Plinius bezweifelt haben, die knidische Aphrodite habe in einem rundum offenen (oder zu öffnenden) Gebäude gestanden - also einem Monopteros(?) ${ }^{55}$ - und stattdessen eine völlig singuläre, höchst merkwürdige Aufstellung in einem kleinen, engen Naiskos mit zwei gegenüber liegenden

54 Dieses Detail des Einschließens fehlt in den übrigen Erwähnungen der Episode (Plin. NH 7, 127 und 36, 21; Philostratos, Vita Apollonii 6, 40; Tzetzes, Chiliades 8. 375-387), weshalb sie auch nicht als Beweis für einen geschlossenen Tempelbau auf Knidos herhalten kann. Das es sich bei der Geschichte zudem um eine beliebte 'Wanderanekdote' handelt, die auch über andere Bildwerke erzählt wurde, hat Blikenberg (s. Anm. 31) 212-216 herausgearbeitet.

55 Plin. NH 36.20: „Aedicula eius tota aperitur, ut conspici possit undique effigies deae, fevente ipsa, ut creditur, facta. Nec minor est ex quacumque parte admiratio est ${ }^{\alpha}$. Die

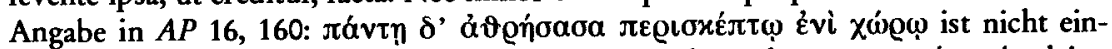

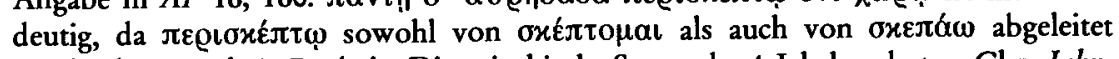
werden kann (vgl. A. Borbein, Die griechische Statue des 4. Jahrhunderts v. Chr., Jabrbuch des Deutschen Archäologischen Instituts 88, 1973, 43-212, bes. Anm. 633). Die

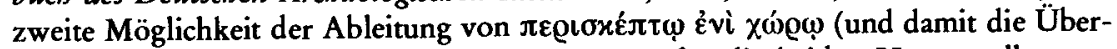
setzung "von allen Seiten geschützt ${ }^{*}$ ) liegt $\mathrm{m}$. E. für die beiden Homerstellen, aus denen der Ausdruck genommen ist, näher als die übliche Übersetzung "von allen Seiten sichtbar ${ }^{*}$ oder ,weithin sichtbar", denn in Od. 1, 426 bezieht sie sich auf das Schlafgemach des Telemachos und in 10, 211 auf den Palast der Kirke, welcher von Bergen und gefährlichen wilden Tieren umgeben ist, also jeweils auf Orte, bei denen der Schutz wichtiger zu sein scheint als die Sicht(barkeit). Bezogen auf Knidos könnte die Formulierung demnach die Umhegung durch die Architektur, in der die Statue aufgestellt war, bezeichnen, wobei es sich hier jedoch nicht um eine geschlossene Cella handeln muss, sondern auch die Säulen eines Monopteros, eine niedrige Balustrade oder Schrankengitter gemeint sein könnten. Doch bleiben nicht nur die übliche Lesart in Über einstimmung mit Plinius, sondern auch Borbeins Vorschlag, die Formulierung des Epigramms bezöge sich auf die Lage des gesamten Heiligtums oder gar der Stadt („weithin sichtbar") sowie eine gezielte Mehrdeutigkeit der Formulierung möglich. Die plinianische Formulierung jedoch auf „literarische[...] Topik [...], welche mit einem der berühmtesten Kunstwerke der Antike verbunden war", zurückzuführen (so Borbein ebd.), scheint mir jedoch schon deshalb schwierig, weil es sich nicht um einen Topos in Bezug auf die Statue handelt, sondern um eine - noch dazu mehrdeutige Einzelangabe. 
Türen postulierten.56 Dabei wird die Rundansichtigkeit von Plinius ausdrücklich hervorgehoben und Monopteroi scheinen in hellenistischer Zeit beliebte Aufstellungsorte für Aphroditestatuen gewesen zu sein. ${ }^{57}$ Auch erscheint eine offenere Aufstellung dem Motiv einer sich zum Bade entkleidenden oder nach dem Bade ankleidenden Göttin besser zu entsprechen, als eine kleine, enge Kammer. ${ }^{58}$ Insofern darf man einer Darstellung der Knidia auf einer Münze des Kaisers Maximinus Thrax aus Tarsus (Abb. 11) eventuell doch einen gewissen Wert beimessen, welche die Statue unter einer baldachinartigen Architektur zeigt. ${ }^{59}$

56 Borbein (s. Anm. 55) 173f. 188-194 mit der älteren Lit., gefolgt von vielen jüngeren Arbeiten. Ein Naiskos wie ihn Borbein und seine Nachfolger in der Folge der Geschichte bei Ps.-Lukian postulieren, hätte so klein und eng sein müssen, dass ein Umschreiten der Statue unmöglich gewesen wäre. Ein solcher Bau ist jedoch nicht nur in Knidos nirgends nachgewiesen, sondern wäre für eine Statue von der Größe der Aphrodite auch äußerst ungewöhnlich. Völlig ohne Parallele wäre die nach Borbein nachträglich in diesen Naiskos eingefügte Hintertür, welche die Neugier der Heiligtumstouristen befriedigt hätte.

57 P. W. Lehmann, Roman Wall Painting from Boscoreale in the Metropolitan Museum of Art (Cambridge, Mass. 1953) 118-124. 157; R. A. Tybout, Aedificiorum figurae. Untersuchungen zu den Architekturdarstellungen des früben zweiten Stils (Amsterdam 1989) 315-323; G. Ortolani, Il padiglione di Afrodite Cnidia a Villa Adriana: Progetto $e$ significato (Rom 1998). Der Rundbau auf der oberen Tempelterrasse von Knidos scheint allerdings endgültig aus der Diskussion ausscheiden zu müssen, denn er war nach neueren Untersuchungen der Athena geweiht (s. H. Bankel, Knidos. Der hellenistische Rundtempel und sein Altar. Vorbericht, Archäologischer Anzeiger 1997, 51-71; W. Blümel, Die Inschriften von Knidos 1 (1992) 114f. zu Nr. 178; Ortolani [wie Anm. 57] 107-109).

58 So scheint man sich zumindest in Griechenland das Bad von Göttinnen in der Regel in der freien Natur gedacht zu haben und man sollt überlegen, ob eine Aufstellung der Badenden in einem geschlossenen Raum (wie etwa in der Tholos der Villa Hadriana, s. Ortolani [wie Anm. 57] passim) nicht erst mit einer gewissen Distanzierung vom Darstellungsgegenstand und einer Hervorhebung des Kunstcharakters der Statue einher geht.

59 Ch. M. Havelock, The Aphrodite of Knidos and Her Successors (Ann Arbor 1995) 59 Abb. 4; Havelock erkennt in der Darstellung einen kaiserzeitlichen Bogen und verwirft die Darstellung daher als irrelevant. Eine Statue unter einem freistehende Bogen wäre jedoch höchst ungewöhnlich und ähnliche abgekürzte Darstellung einer baldachinartigen Architektur finden sich auf Münzen häufiger, vgl. etwa kaiserzeitliche Münzdarstellungen der Büste der Tyche von Laodikea und der Julia Domna (W. Wroth, Catalogue of the Greek coins of Galatia, Cappadocia, and Syria (Catalogue of Greek coins in the British Museum, 20) [Bologna 1964] Laodicea ad Mare Nr. 78 Taf. 30, 8; Nr. 81 Taf. 30, 9); der Nemesis von Nikopolis (ebd. Nicopolis Nr. 2 Taf. 31, 10); der Stadtgöttin von Caesarea Marittima (G. F. Hill, Catalogue of the Greek coins of Palestine [Galilee, Samaria, and Judaea] [Catalogue of the Greek coins in the British Museum, 27] [Bologna 1965] Caesarea Nr. 39 Taf. 3, 1; Nr. 41 Taf. 3, 2) oder der Stadtgöttin von Diospolis (ebd. Diospolis-Lydda Nr. 3-4 Taf. 5, 5-6). 


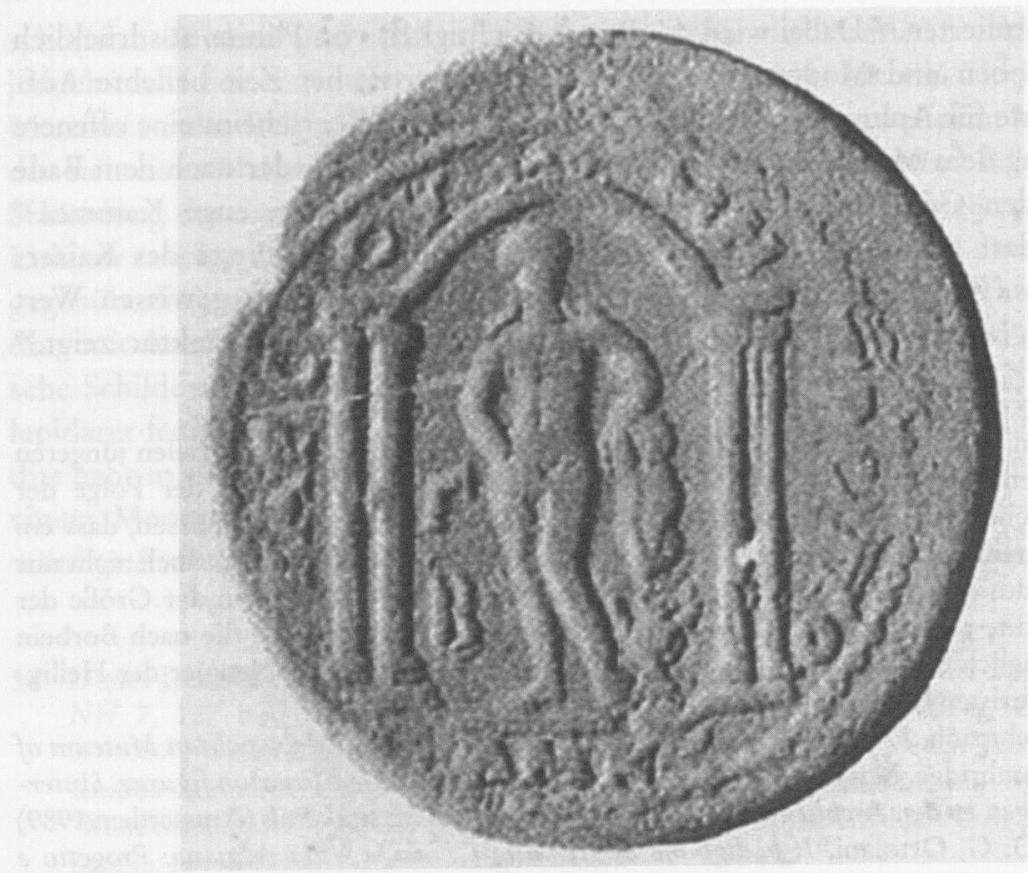

Abb. 11: Bronzemünze aus Tharsus, 235-238 n. Chr.

Doch unabhängig davon, für wie glaubhaft man die Angabe des Plinius hält, so haben die Archäologen, beeindruckt von der lebhaften Beschreibung, völlig unterschätzt, dass die Beschreibung Pseudo-Lukians in allererster Linie eine ganz maßgebliche Funktion zur Verdeutlichung der Pointe der Geschichte besitzt, indem die Behauptung, die Statue sei nur von zwei Seiten zu sehen gewesen, der Betonung der Opposition der erotischen Präferenzen entspricht, ${ }^{60}$ während Rundansichtigkeit den springenden Punkt der Geschichte erheblich verunklärt hätte. Für die Rekonstruktion des Heiligtums von Knidos eignet sich die Geschichte demnach nicht, doch wird sie dadurch für die Archäologie nicht unbedeutend. Sie gibt vielmehr Aufschluss über unterschiedliche Interessen und Wahrnehmungsweisen bei der Betrachtung antiker Skulptur. ${ }^{61}$

60 Dazu ausführlich S. Goldhill, Fouault's Virginity. Ancient Erotic Fiction and the History of Sexuality (Cambridge 1995) 102-111. Havelock (s. Anm. 59) $61 \mathrm{f}$.

61 Z. B. R. Osborne, Looking on - Greek Style. Does the sculpted girl speak to women too? in: I. Morris (ed.), Classical Greece: Ancient histories and modern archaeologies (Cambridge 1994) 81-96; N. Spivey, Understanding Greek Sculpture: Ancient Meanings, Modern Readings (London 1996) 178-183. Ein weiteres instruktives Beispiel ist die Einleitung zu Euripides' Ion, in der die Dienerinnen der Kreousa die Bildwerke vor und an dem delphischen Apollontempel diskutieren. Auch hier weicht die 
Und was sagen uns schließlich die gänzlich unrealistischen literarischen Bilder? Zum einen können sie uns helfen, die spezifischen Eigenheiten und Wirkungsfelder realer bildlicher Darstellungen der Antike und insbesondere ihre Grenzen besser zu erkennen. Aber erinnern nicht selbst die elaborierten und oft faszinierenden Versuche der Dichter und Redner, die bildende Kunst im Wort zu übertreffen, ein wenig an das laute Pfeifen im dunklen Wald? Vielleicht ist die größere Vorliebe für die Allegorie in der Wortkunst gerade als Reaktion auf die (vermeintlichen) Defizite ihres Genres zu verstehen. Jedenfalls scheint der Wettstreit der Künste weiterhin offen zu sein, wenn die beeindruckendsten Wortkunstwerke ein implizites Eingeständnis der Macht des Visuellen sind, über deren Wirken auf die antike Gesellschaft wir andererseits ohne sie nur wenig wüssten.

\section{Abbildungsnachweise}

Abb. 1: Florenz, Uffizien 1704, nach J.M. Massing, Du texte à l'image. „La Calomnie ${ }^{\alpha}$ $d^{\prime}$ Apelle et son iconographie (Strasbourg 1990) Taf. 4 A.

Abb. 2: Neapel, Museo Nazionale H 3253, nach: FR Taf. 88.

Abb. 3: Athen, Nationalmuseum 447, Slg. Demetriou, nach K. M. C. Dunbabin - M.W.

Dickie, Invidia rumpantur pectora. The Iconography of Phthonos/Invidia in GraecoRoman Art, Jabrbuch für Antike und Christentum 26, 1983, Taf. 4 a.

Abb. 4: Athen, Nationalmuseum 447, Slg. Demetriou, nach K.M.C. Dunbabin - M. W.

Dickie, Invidia rumpantur pectora. The Iconography of Phthonos/Invidia in Graeco-

Roman Art, Jabrbuch für Antike und Christentum 26, 1983, Taf. 4b.

Abb. 5: London, British Museum E775, Trustees of the British Museum, London.

Abb. 6: London, British Museum 2191, nach: D. Pinkwart, Das Relief des Archelaos von

Priene, Anitke Plastik 4, 1965, Taf. 28.

Abb. 7: Turin, Museo Archeologico, o. Inv., Inst. Neg. Rom 82.3453.

Abb. 8: Zeichnung Albrecht Dürers, nach F. Koepp, Ogmios. Bemerkungen zur gallischen Kunst, Bonner Jabrbücher 125, 1919, Taf. 4, 1.

Abb. 9: Oxford, Ashmolean Museum 573, nach F. Koepp, Ogmios. Bemerkungen zur gallischen Kunst, Bonner Jabrbücher 125, 1919, Taf. 4, 2.

Abb. 10: Rom, Vatikan 812, nach Inst. Neg. Rom 68.3650.

Abb. 11: ehem. Kunsthandel, nach Ch.M. Havelock, The Apbrodite of Knidos and Her Successors (Ann Arbor 1995) Abb. 4.

Beschreibung vom archäologischen Befund ab. Während dies sich jedoch durch die Funktion erklärt, welche die Beschreibungen für das Verständnis des Tragödiengeschehens haben, zeigt die Passage zugleich, dass die Versuche der Forschung, den Bildschmuck von Heiligtümern und anderen öffentlichen Orten im Sinne seines identitätsstiftenden Potentials zu deuten, antikem Denken völlig angemessen sind; vgl. F. Zeitlin, The artful eye: vision, ecphrasis and spectacle in Euripidean theatre, in: Goldhill - Osborne (s. Anm. 1) 147-156. 